OPEN ACCESS

Edited by:

Mariusz Cycoń

Medical University of Silesia, Poland

Reviewed by:

Chao Zhao,

Fujian Agriculture and Forestry

University, China

Datta Madamwar,

Sardar Patel University, India

*Correspondence:

Ashwani Kumar

ashwaniiitd@hotmail.com

Specialty section:

This article was submitted to Microbiotechnology, Ecotoxicology and Bioremediation,

a section of the journal

Frontiers in Microbiology

Received: 15 March 2018 Accepted: 14 May 2018

Published: 04 June 2018

Citation:

Malla MA, Dubey A, Yadav S,

Kumar A, Hashem A and Abd_Allah EF (2018) Understanding and Designing the Strategies for the Microbe-Mediated Remediation of Environmental Contaminants Using

Omics Approaches

Front. Microbiol. 9:1132.

doi: 10.3389/fmicb.2018.01132

\section{Understanding and Designing the Strategies for the Microbe-Mediated Remediation of Environmental Contaminants Using Omics Approaches}

\author{
Muneer A. Malla ${ }^{1}$, Anamika Dubey ${ }^{2}$, Shweta Yadav ${ }^{1}$, Ashwani Kumar ${ }^{2 *}$, Abeer Hashem ${ }^{3}$ \\ and Elsayed Fathi Abd_Allah ${ }^{4}$ \\ ${ }^{1}$ Department of Zoology, Dr. Harisingh Gour University, Sagar, India, ${ }^{2}$ Metagenomics and Secretomics Research Laboratory, \\ Department of Botany, Dr. Harisingh Gour University, Sagar, India, ${ }^{3}$ Department of Botany and Microbiology, College of \\ Science, King Saud University, Riyadh, Saudi Arabia, ${ }^{4}$ Department of Plant Production, College of Food and Agricultural \\ Sciences, King Saud University, Riyadh, Saudi Arabia
}

Rapid industrialization and population explosion has resulted in the generation and dumping of various contaminants into the environment. These harmful compounds deteriorate the human health as well as the surrounding environments. Current research aims to harness and enhance the natural ability of different microbes to metabolize these toxic compounds. Microbial-mediated bioremediation offers great potential to reinstate the contaminated environments in an ecologically acceptable approach. However, the lack of the knowledge regarding the factors controlling and regulating the growth, metabolism, and dynamics of diverse microbial communities in the contaminated environments often limits its execution. In recent years the importance of advanced tools such as genomics, proteomics, transcriptomics, metabolomics, and fluxomics has increased to design the strategies to treat these contaminants in ecofriendly manner. Previously researchers has largely focused on the environmental remediation using single omics-approach, however the present review specifically addresses the integrative role of the multi-omics approaches in microbial-mediated bioremediation. Additionally, we discussed how the multi-omics approaches help to comprehend and explore the structural and functional aspects of the microbial consortia in response to the different environmental pollutants and presented some success stories by using these approaches.

Keywords: environmental pollution, metagenomics, metatranscriptomics, proteomics, metabolomics, fluxomics, bioremediation

\section{INTRODUCTION}

The quality of life on Earth is inevitably related to the overall quality of the environment. As human activity has increased around the globe, the Earth has been contaminated with a large number of toxic pollutants from multiple sources (Raghunandan et al., 2014, 2018). The shrinking of natural resources, an increase in pollution and carbon emissions and other problems related to human 
health are the consequence of industrialization and have proven disastrous for every global region (Ahuti, 2015). Industrialization not only entails hi-tech innovations but also affects the economic and social transformation of human societies (Mgbemene et al., 2016). The industrial revolution, has resulted into hazardous health problems that are amplified by the large-scale environmental contaminations (Figure 1). The advancements in the field of technology and industrialization, brings with them, their obnoxious partners, pollution as well as degradation of the environment. These revolutions have led to both intentional and accidental discharges of toxic gases, chemicals, and xenobiotics into the environment.

Environmental contamination is a pertinacious problem and continues to be a burden to human health. While a number of approaches have been used to monitor and reduce this problem, it remains a difficult issue. Globally, both the environment and humans are affected by these hazards. To safeguard both humans and environment from the adverse consequences of environmental pollution novel approaches must be designed, and bioremediation is one such approach. Interest in the microbialbased bioremediation of contaminants has increased in recent years, as people endeavor to find sustainable ways of remediating polluted environments (Raghunandan et al., 2014, 2018; Kumar et al., 2016). The biotransformation and bioremediation-based methods strive to harness the naturally occurring microbial catabolic diversity to degrade, transform or accumulate vast amounts of problematic compounds, including radionuclides, metals, pharmaceutical substances, polyaromatic hydrocarbons (PAHs), and polychlorinated biphenyls (PCBs). Advancements in NGS (next generation sequencing) in recent years has allowed detailed genomic, metagenomic, and bioinformatic analyses of environmentally important microorganisms, thereby providing unprecedented insights into key biodegradative pathways. Mukherjee et al. (2017), studied the microbial responses to hydrocarbon-contaminated environments and suggested that substantial taxonomic and functional variation occurs in different geographically and spatially isolated oilpolluted sites. In addition to providing significant analytical and visual methods for understanding the relation between the soil microbiome and ecosystem functioning, their study provided novel insights into the ecological dynamics of hydrocarbon-contaminated sites. A study carried out by Luo et al. (2014) revealed that soil microbial diversity varies in response to heavy metal contamination. Hauptmann et al. (2017) investigated microbial metagenomes from the ice sheets of Greenland and isolated potential microbial genes for the degradation and resistance to contaminants, such as heavy metals (lead and mercury), polycyclic aromatic hydrocarbons (PAHs), and polychlorinated biphenyls (PCBs). Similar studies were carried out by Joshi et al. (2014) that investigated the metagenomes isolated from petroleum muck, which revealed the indigenous microbial communities inhabiting the petroleumcontaminated sites. Recently, a number of research papers (George et al., 2011; Kumavath and Deverapalli, 2013; Bell et al., 2014; Pushpanathan et al., 2014; Ufarté et al., 2015; Czaplicki and Gunsch, 2016; Chistoserdova, 2017) have been published wherein different authors have emphasized individual genomic or transcriptomic approaches in bioremediation of environment. Previously researchers has largely focused on the environmental remediation using single omics-approach,

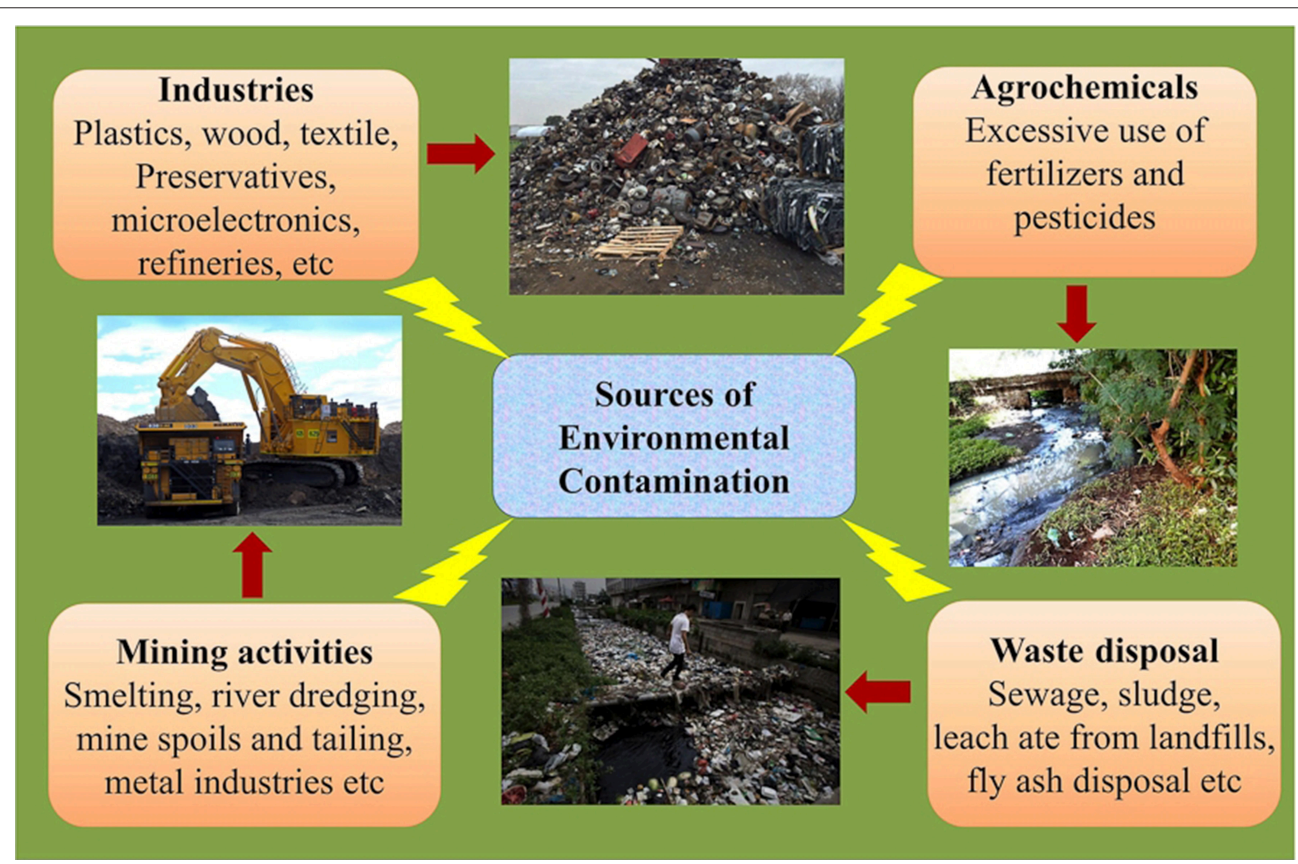

FIGURE 1 | Different sources of environmental contamination. 
however the present review specifically addresses the integrative role of the multi-omics approaches in microbial-mediated bioremediation. Additionally, we discussed how the multi-omics approaches help to comprehend and explore the structural and functional aspects of the microbial consortia in response to the different environmental pollutants and mentioned some success stories by using these approaches.

\section{MECHANISM OF THE BIOREMEDIATION PROCESS}

Bioremediation is the application of microbes to degrade environmental pollution. It is an ecologically sound and state of art practice that utilizes microbial processes to completely remove the toxic contaminants. Microorganisms are not only important in regulating the biogeochemical cycles (Griggs et al., 2013), perpetuating the atmosphere (Morris et al., 2011), keeping us healthy and suppressing the plant diseases and helping them to grow (Pineda et al., 2017) but also play their part in cleaning of environmental pollutants (Morris et al., 2011). Microbial mediated bioremediation is of great significance because it promises a cheaper, simpler and more environmentally friendly method when compared to the more commonly employed "muck, suck and truck" non-biological remedial methods, in which the contaminants are simply pumped up or dug out and are then shipped elsewhere (Lovley, 2003). However, the promise of bioremediation is yet to be fully realized. One reason for this is that bioremediation approaches that are successful at one location may not be effective in other locations. Additionally, the microbial processes that remediate pollutants under lab conditions may fail to perform adequately in the field. The reasons for such failures are, however, unclear, and as a result many managers are unwilling to use bioremediation as an option for environmental clean-up. Moreover, the mechanisms that control the growth and activity of microorganisms in contaminated environments are not well understood, thereby limiting the implementation of bioremediation (Lovley, 2003). Dynamic behavior, nutritional flexibility and knack of adapting to extreme environmental conditions make microbes the most suitable life forms for endurance. This feature of microbes is advantageous and beneficial to the mankind particularly when it comes to elimination of pollutants and other toxic compounds from the environment. Microbes have the tendency to degrade contaminants from the environments and do so via diverse enzymatic process, thus mitigating or removing the environmental contaminations (Lovley et al., 1991). An extensive list of the microbes that carry out the bioremediation processes is available (Satyanarayana et al., 2012; Prakash et al., 2013; Abou Seeda et al., 2017). Microorganisms can carry out environmental restoration through a diverse array of processes, such as binding, oxidation, volatilization, and immobilization or by chemical transformation of the pollutants. One of the most common types of the bioremediation technique is the oxidation of the toxic organic pollutants to the harmless products (Figure 2). Oxygen the most common electron acceptor for microbial respiration as well as the agent for the aerobic degradation of wide range of organic pollutants ranging from arenes such as from benzene to xenobiotics (pesticides) has been studied in detail (Wackett and Hershberger, 2001). While a vast phylogenetic diversity is able to degrade aerobic pollutants (Wackett and Hershberger, 2001), but Pseudomonas species and its close associates are the most intensively investigated organisms due to their ability to degrade many different contaminants.

Ideally, bioremediation approaches should be designed based on knowledge of the particular microorganisms inhabiting the contaminated areas, including their metabolic processes and how the microorganisms react to changes in the environmental conditions. Unfortunately, in practice, this specialized knowledge is not easily available, and the use of microbes in bioremediation is extremely experimental rather than knowledge-based. Although at present the science of bioremediation is still far from ideal, it now seems achievable. Common terminologies used in this article are given in Table S1.

\section{STRATEGIES TO STUDY MICROBIAL MECHANISMS WITH AN AIM TO EXPEDITE THE BIOREMEDIATION PROCESS}

\section{Pre-genomics Access to Bioremediation: Culture-Based Techniques}

Microbes are the most diverse and profuse forms of life on earth, and they emerge as key players in important ecological processes, such as organic matter putrefaction, soil structure formation, and the recycling of important chemical elements. Thus, microbes play a vital role in regulating the global biogeochemical cycles (Garbeva et al., 2004). Knowledge regarding microbial dynamics and their interactions with biotic and abiotic factors is an indispensable tool in the fields of bioremediation, biotechnology, pharmacy and energy production processes. Currently, the majority of studies that are related to bioremediation processes rely on the "treatability study," in which samples from contaminated sites are typically incubated under laboratory conditions, and the rates at which the contaminants are immobilized or degraded are recorded (Head et al., 2003). These studies provide an estimate regarding the potential metabolic activities of the microbial consortia but give little insight into the microbes responsible for bioremediation. When bioremediation processes are studied more precisely, an effort is made to isolate and characterize the organisms that are responsible for remediation (Head et al., 2003). The major drawback of culture-dependent techniques is that greater than $99 \%$ of microbes that inhabit the diverse natural environments are either uncultivable or are very difficult to culture (Vartoukian et al., 2010; Dickson et al., 2014; Bursle and Robson, 2016). The recovery of microbial isolates that are responsible for bioremediation processes is invaluable because the study of these isolates provides an opportunity to scrutinize their biodegradation reactions, along with other physiological aspects that are liable to control growth and other activities in the polluted environments. To overcome these limitations and drawbacks, a number of DNA-based molecular techniques 


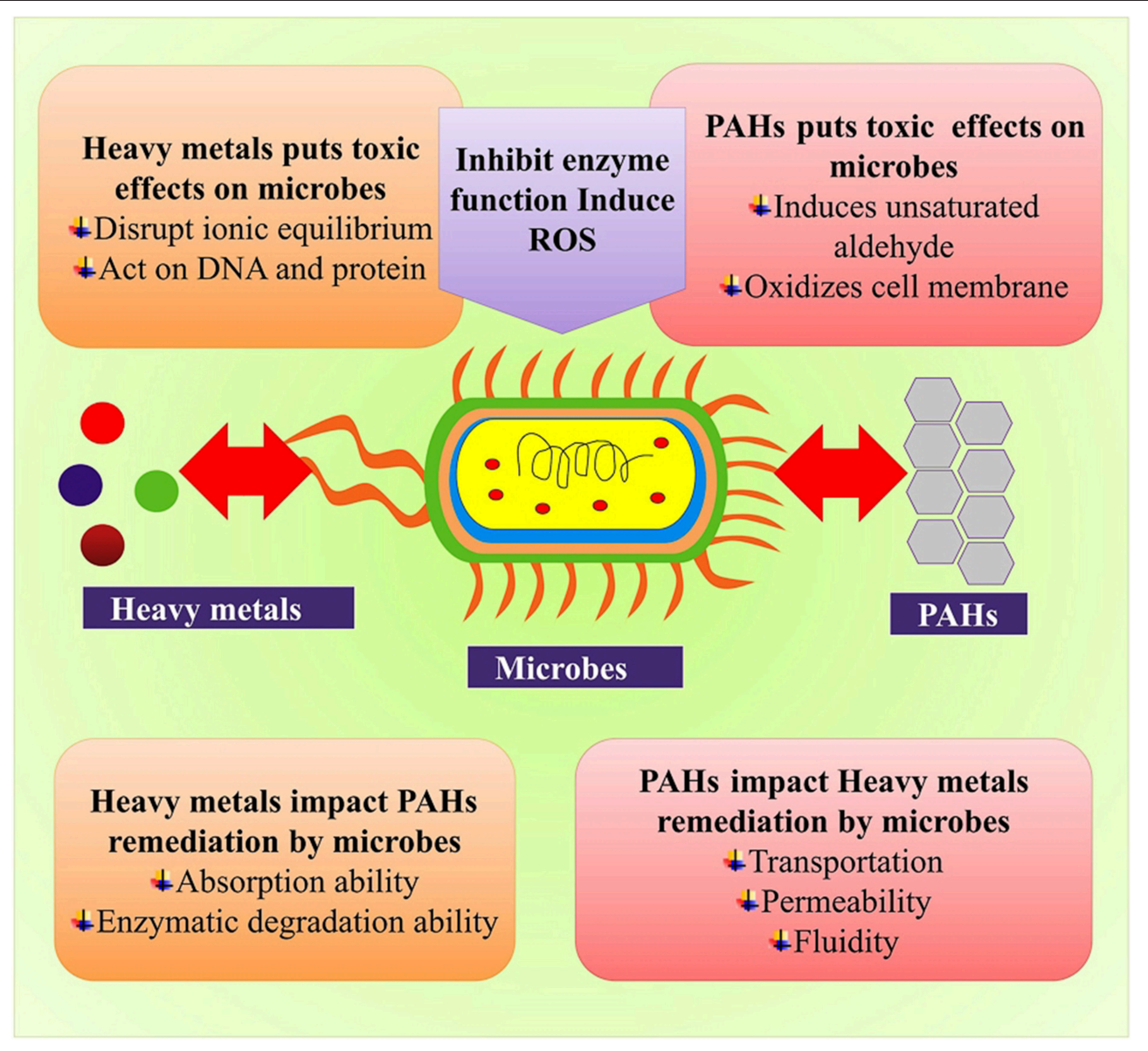

FIGURE 2 | Microbial-based bioremediation mechanism.

have been devised to explore the microorganisms responsible for bioremediation.

\section{Molecular Approaches to Study Microbial Bioremediation}

For years microbiologists have sought a reliable technique to ascertain the microbial diversity in environmental samples. A number of molecular methods have been developed for this purpose. The development of the analysis of 16S rRNA gene sequences has significantly enhanced our ability to understand and explore the microbial world (Armougom and Raoult, 2009; $\mathrm{Ju}$ and Zhang, 2015). This has countered the idea that only a small percentage of the bacteria are isolated using culturing methods (Carroll and Patel, 2015). Denaturing gradient gel electrophoresis is applied in the field of microbial ecology to profile the complex microbial diversity and is devoid of the biases inherent in culture analysis (Fakruddin and Mannan, 2013). Molecular-based approaches such as denaturing gradient gel electrophoresis allows the separation of 16S rRNA genes based on the decreased electrophoretic mobility of partially melted double stranded DNA (dsDNA) in polyacrylamide gel that contains either a linear gradient of temperature or a linear gradient of DNA denaturant (a mixture of formamide and urea). The primary advantage of this technique is that it generates a profile of the entire diversity of the microbial community by separating a mixed population of $16 \mathrm{~S}$ rRNA gene products. However, these techniques have several limitations, biases, and drawbacks. For example, the dominant populations are better revealed, and the bands obtained from multiple numbers of species may be obscured behind a single band, thereby leading to an underestimation of the microbial diversity (Satokari et al., 2001; Gafan and Spratt, 2005; Green et al., 2010). Recently, DGGE based analysis of $16 \mathrm{~S}$ rRNA sequences has been used to investigate and profile complex microbial diversity and to deduce the phylogenetic affiliation among these microbial communities (Nishimura et al., 2010).

\section{ROLE OF OMICS-APPROACHES IN MICROBIAL BIOREMEDIATION}

Microbial-bioremediation process utilizes the indigenous microbial communities to clean up the environmental contaminations. The rate at which the contaminants are detoxified depends on a number of factors such as the 
composition of the indigenous microbial communities, nature, and extent of the pollutant and environmental conditions (Chakraborty et al., 2012). Thus, the optimization of the bioremediation process demands the combination of various complex variables, to understand and envisage the fate of environmental pollutants. Molecular approaches such as genomics, proteomics, transcriptomics, metabolomics, and fluxomics are now consistently finding their applications in bioremediation process so as to understand the exact mechanism involved. the advent of NGS methods and in silico analyses have enabled the environmental microbiologists to address these problems and has helped them to open up the microbial "balckbox" in contaminated environments (Maphosa et al., 2010). A number of microbes haves been reported that carry out the degradation of different environmental contaminants (Table 1). The application of omic-tools for the taxonomic and functional aspects of the microbial communities from contaminated sites has led to the discovery of some novel bacteria that otherwise were not accessible by using the traditional culturing techniques. Recently, high through-put omics-approaches have been employed to explore the systems biology of the microbial consortia in myriad of environments. However, the successful implementations of these multifaceted bioremediational approaches necessities a much detailed and comprehensive understanding of the factors that govern the growth, metabolism, structure, dynamics, and functions of the indigenous microbial consortia of these sites. Here is where the recent advances and breakthroughs in genomics, metatranscriptomics, metaproteomics metabolomics, and fluxomics along with in silico (bioinformatics) analysis play their part by providing key in-sights in understanding and exploring the microbial communities and their mechanisms in the bioremediation of environmental contaminants. These approaches have made it practically possible and economically feasible to explore the metagenomes of contaminated environmental samples, harboring diverse microbial communities. This has not only provided an insight regarding the diversity, but also putative information about the meta-functionality of the microbial populations inhabiting the contaminated environments. Even the combination of data generated via different omic-approaches may be used to study the microbial metabolism during the bioremediation processes. Studies like these will provide an opportunity to develop efficient strains of microbes, so as to improve metabolism of different xenobiotics (Desai et al., 2010). The efficiency of the bioremediation will definitely be increased if the precise molecular approaches are properly used and scientifically pursued.

Combined results from various "omics tools" has offered key insights regarding the survival, metabolism, and interaction of the microorganisms in their native environments including gut microbiomes (Gill et al., 2006), deep-sea sediments ( $\mathrm{Hu}$ et al., 2010), groundwater and marine systems (DeLong, 2005; Benndorf et al., 2007; Hemme et al., 2010), and extreme milieus (Baker and Banfield, 2003). In order to expedite the complete remediation of contaminated environments a comprehensive understanding of the physiology, biochemistry, ecology, and phylogeny of the indigenous microbial consortia of contaminated sites is warranted. The application of genome-based techniques in the investigation of both environmental samples and pure cultures makes it possible to build the models that are required to predict the activity of microbes under diverse bioremediation strategies (Figure 3).

\section{Culture-Independent Insight: Metagenomics}

The field of metagenomics is undergoing a rapid evolution amid the arrival of next generation sequencing technologies. The science of metagenomics has bypassed the need for cloning and has facilitated a new approach of comparative metagenomics. Advances in high-throughput technology have revolutionized the field of microbiology. Metagenomics, a rapidly growing and young field of research, aims to investigate uncultured organisms in order to understand the true diversity of microbes, their functions, cooperation, interactions, and evolution within diverse environments. A relatively new approach of molecular biology, metagenomics was used for the first time by Handelsman et al. (1998) while studying the chemistry of unknown soil microbes. Metagenomics involves a culture-independent sequencing-based analysis of DNA that is isolated from the environmental samples, i.e., metagenomes (Daniel, 2005). Sequence phylotyping provides reliable information regarding both diversity (What microorganisms are there?) and function (What can the microorganisms do?). Metagenomics has helped us in closing the gap left by culturing techniques and has provided insights into in situ microbial structures, dynamics and functioning thereby enhancing bioremediation processes.

\section{APPROACHES TO METAGENOMIC ANALYSIS}

Metagenomic approaches generally fall into one of two categories: function based or sequence-based. Together, these approaches have increased our understanding of the unculturable microbial world and have, therefore, also provided insights into the prokaryotic world that is otherwise obscure.

\section{Sequence-Based Analysis}

Sequence-based metagenomic analysis provides microbial information irrespective of culturing. In comparison to functional screening, the sequence-based approach depends on the sequence analysis to provide a basis for function prediction. Substantial databases are catalogd in the "Environmental Genome Sequence" database, and the sequencing assignments become more instructive and informative over time because data are continuously compiled from diverse sources. Sequence-based metagenomic analysis can be used for gene identification, genome assemblages, clarifying complete metabolic pathways and comparing organisms from different communities. 


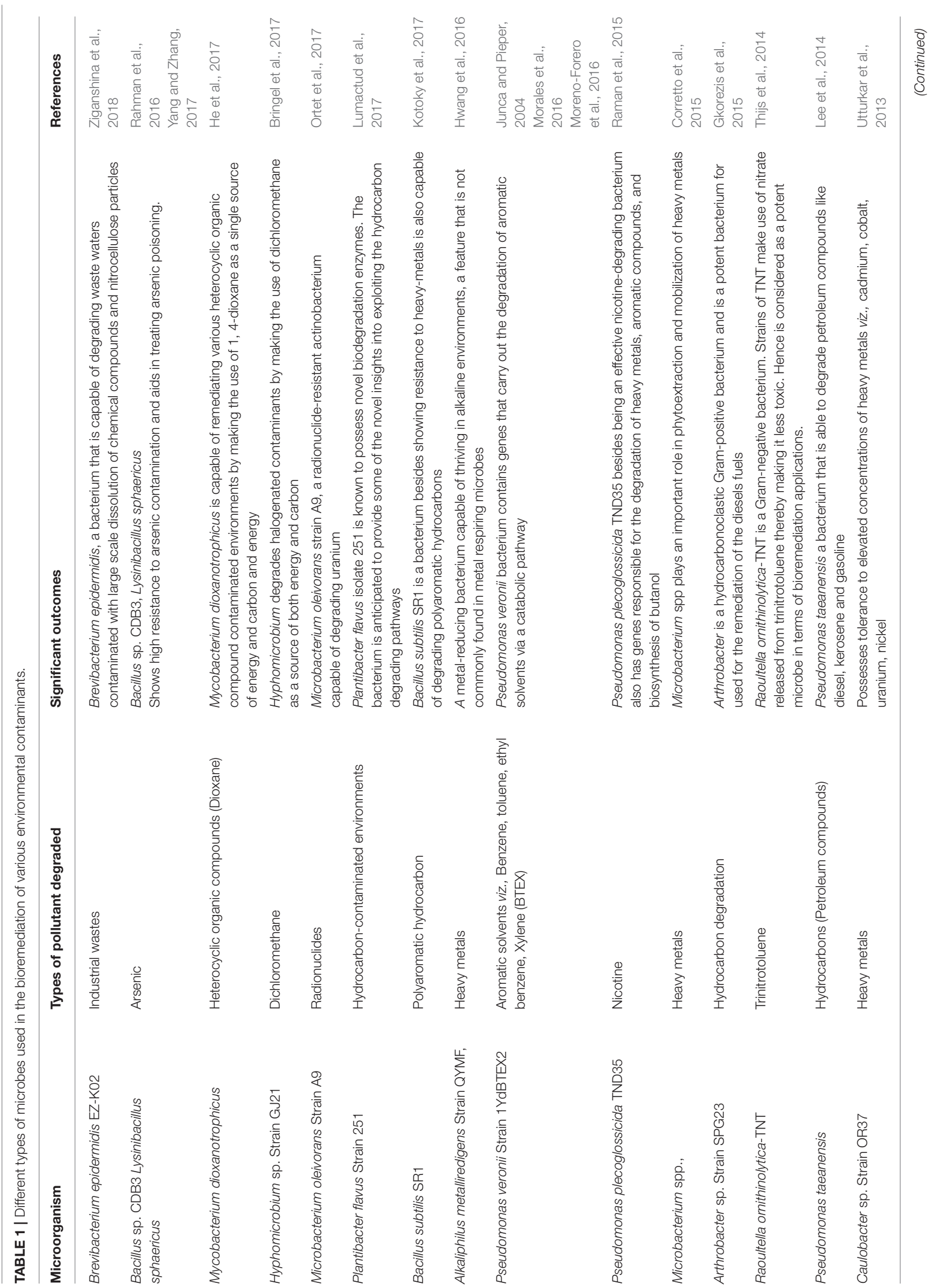




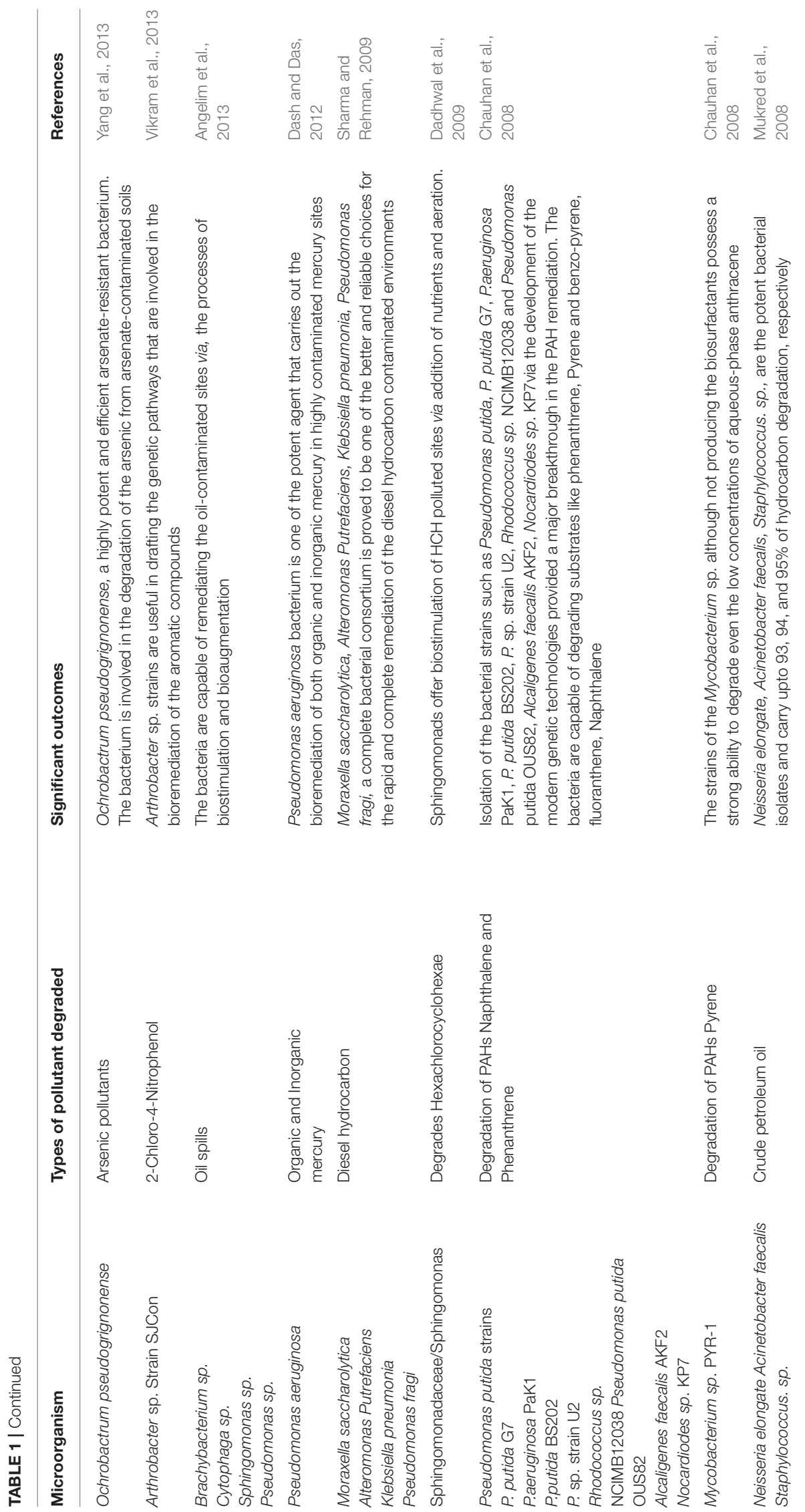




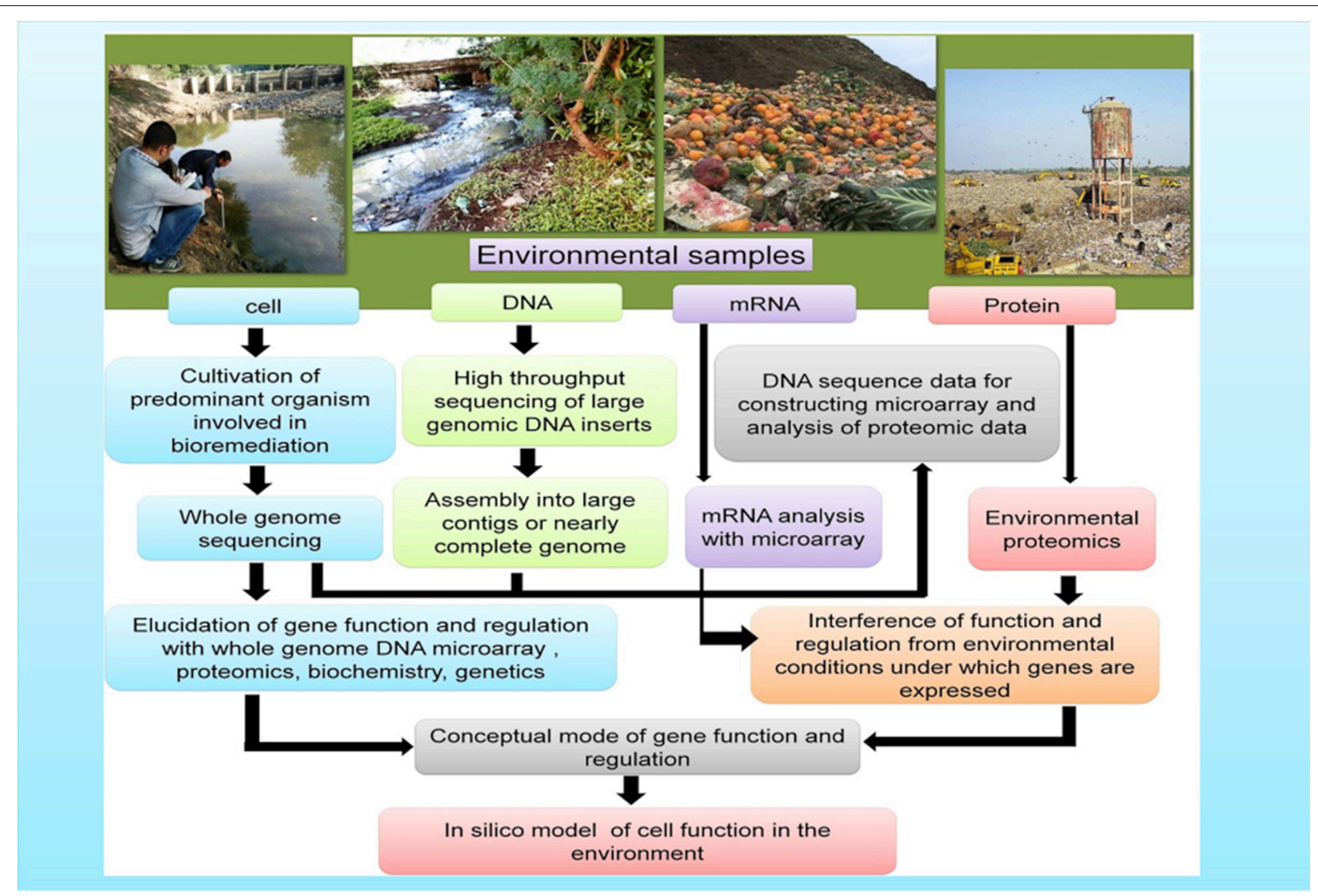

FIGURE 3 | Genome-based approaches that contribute toward the development of models of how microbes function in the polluted environments (a) Cells: the isolated cells from the environmental samples gives an opportunity to furnish/obtain information on the gene composition as well as in-depth physiological analysis (b) DNA: Genomic DNA extracted from the environmental samples provides information and knowledge regarding the genetic potential of the yet-unculturable microorganisms (c) mRNA and Proteins: mRNA and proteins extracted from the environments furnishes information about the gene expression under varied environmental conditions.

\section{Function-Based Analysis}

Functional metagenomics is a potent and powerful method for studying the functional aspects of genes. Functionbased metagenomic analysis involves isolating DNA from environmental samples to study the functions of the encoded proteins (Lam et al., 2015). In functional-based metagenomic analysis, DNA fragments are cloned, expressed in a laboratory host and screened for enzymatic activities. The function-based metagenomic approach allows the discovery of novel genes, and metagenomic sequencing offers unique opportunities to explore novel environments that have yet to be studied. Functional analysis plays a pivotal role in these studies by giving important information regarding the metabolic and functional diversity (Prakash and Taylor, 2012).

\section{METAGENOMICS IN BIOREMEDIATION}

Environments where anthropogenic activities are widespread have often been contaminated by various types of toxic compounds (Pacwa-Płociniczak et al., 2011). This contamination varies and affects the most important aspects of our ecosystem, such as the air, water, and soil (Saharan et al., 2012). The relationship between species diversity and ecosystem function has long been an area of interest (Sutherland et al.,
2013). Disturbances caused by anthropogenic activities, such as contamination by hydrocarbons (van Dorst et al., 2014) and heavy metals (Pessoa-Filho et al., 2015), can strongly affect the microbial diversity and structural composition. Next generation sequencing provides an opportunity for extensive analysis of environmental genomes. Metagenomics, along with other molecular techniques, has revolutionized the field of microbiology by focusing on microbial diversity, evolution and adaption (Riesenfeld et al., 2004). Studies that have investigated the microbial communities from diverse environments, such as sediments and marine water (DeLong et al., 2006; Yooseph et al., 2007), the human gut (Turnbaugh et al., 2007), soils (Smets and Barkay, 2005), and acid mine drainage (Tyson et al., 2005), have generated novel insights into the metabolism, community structure, evolution, function, and genetic makeup of these communities. Metagenomic analysis presents an exceptional opportunity to comprehensively analyse the response of an ecosystem to environmental changes; however, as yet, there are no reported studies that have examined the adaptation and response of microbial communities to environmental pollutants. Metagenomics holds great promise for the field of bioremediation, as it will help to shape the approach to bioremediation in a number of interconnected ways (Satyanarayana et al., 2012; Tripathi et al., 2018). 
Metagenomic bioremediation offers more positive results with better degradation ratios when compared to other approaches to bioremediation (Kosaric, 2001). First, metagenomics has greatly increased our understanding of how microbes develop "bucket-brigades" for the degradation of xenobiotic compounds, thereby allowing the differentiation of contaminated sites into areas where the native microbiota is able to remediate the environmental status by using intensive ex situ treatment or by in situ bioaugmentation. Second, it will help to identify key microbial processes and will specify how the community composition could best be complemented to enable mineralization of a pollutant when metabolic crosstalk among different species is necessary, and is, therefore, carried out by bacterial consortia rather than by individual species (Bedard et al., 2006; Supaphol et al., 2006; Thomas et al., 2012). Third, metagenomics will provide appropriate metagenomic databases that will offer a rich stock of genes for the construction of novel microbial strains for targeted use in bioremediation efforts. Microbiologists consider the metagenomics-based bioremediation approach to be one of the most important and potent tools for the eradication of pollutants from the environment (Mazaheri Assadi and Tabatabaee, 2010; Satpute et al., 2010; Chandran and Das, 2011).

\section{METATRANSCRIPTOMICS AND PROTEOMICS IN BIOREMEDIATION}

Metagenomics is an enormously potent tool by which the genetic makeup of the microorganisms inhabiting any environment can be described. However, metagenomics offers limited functions in elucidating gene expression and activity. The rapid development of metatranscriptomics (Poretsky and Ann Moran, 2011) and metaproteomics (Verberkmoes et al., 2009b) has made it possible to predict the functional activities of the microbial consortia. Metatranscriptomic studies can be used to ascertain the activity of genes within a given environment. The expression of the functional genomes within environmental samples can be determined by metatranscriptomics. Metatranscriptomics is of great interest for research related to environmental remediation. Recently, transcriptomic studies have been applied to the tdfA gene (an herbicide degrading gene), and the gene was successfully quantified (Nicolaisen et al., 2008). Although a number of studies have been carried out regarding the discovery and diversity of the functional genes in environmental samples, few studies have thoroughly compared their findings with actual bioremediation rates calculated from real biodegradation events (Jørgensen, 2007; Winderl et al., 2007).

Environmental proteomics offers better results when combined with other "omic" approaches, such as transcriptomics and metabolomics. To date, protein profiling related to the treatment of contaminated environments has primarily used SDS-PAGE (1D) to characterize the microorganisms and the ecology that is involved in the bioremediation process. Since ecological studies primarily focus on the natural adaptation of the microbes to the environments they inhabit, proteomics has been applied in studies that have provided insights into the mechanisms of adaptation, particularly to thermophilic conditions. The proteins of hyperthermophilic microorganisms are of great significance, as they possess an improved conformational stability that allows the thermophiles to remain active at elevated temperatures. By making the use of this property, the molecular basis of protein folding and conformational stability can be predicted. Proteomic approaches have often been employed to gain a more complete understanding of the physiological responses of microbes to xenobiotics, temperature changes and other stressors (Lacerda and Reardon, 2009). Proteomics approaches are also helpful in analyzing the physiological changes that microbes undergo during bioremediation. Despite lacking metagenomic sequences, Wilmes and Bond (2004) were able to explore the microbial mediated phosphorus removal from contaminated water by utilizing a metaproteomic approach. Similarly, Lacerda et al. (2007) used 2D gel electrophoresis in combination with mass spectroscopy and de novo sequencing to identify more than one hundred proteins from microbial communities that were exposed to cadmium contaminated water. Advancements in proteomics technology have led to the identification of novel genes and proteins during the anaerobic degradation of ethylbenzene and toluene, as demonstrated in a study by Ebn et al. (2005). During the anaerobic biodegradation of toluene, a number of genes and associated proteins are expressed. The proteomics approach has revealed novel pathways of aerobic and anaerobic biodegradation of toxins, and therefore it provides a basis for the identification of novel proteins. Regulated proteins are in various metabolic categories, including the general stress response, oxidative stress response, transcription regulation, transport molecules, and energy metabolism (Santos et al., 2004). Konopka and Wilkins (2012) utilized meta-transcriptomics and meta-proteomics to identify and characterize a Geobacter spp. in response to carbon biostimulation alterations. Doré et al. (2015) investigated fungal response under various environmental conditions and identified proteins and extracellular enzymes by making use of "omic" approaches, along with combined liquid chromatography and mass spectrometry techniques.

\section{MICROBIAL METABOLOMICS AND FLUXOMICS IN BIOREMEDIATION}

Metabolomics, the study of the metabolite profiles of a cell within a given set of conditions, is one of the most recent entries to the "omics" family. In addition to genomics, transcriptomics and proteomics, cutting-edge research is now expanding toward the analysis of microbial cellular metabolites. Metagenomics has already solidified its significance by playing an important role in understanding the diversity and functional aspects of the microbial consortia. Application of metabolomebased approaches to the environmental samples has made it possible to develop models that can envisage microbial activities under different bioremediation strategies. Metabolomics allows us to better understand the dynamic operations of the microbial communities and their functional contributions to the environments in which they live. When a microbial cell is 
subjected to an environmental stressor it releases a number of primary and secondary metabolites. The metabolomics approach explores the functional roles of these low-molecular weight metabolites. Recently, a number of studies have made use of microbial metabolome analysis to investigate the biodegradation of anthropogenic pollutants. An example of this is the comparative metabolome analysis of Sinorhizobium sp. during phenanthrene degradation (Keum et al., 2008). In this study, the intracellular metabolomes were compared with those from the carbon sources, and the metabolite profiles (fatty acids, polyhydroxy alkanoates, and polar metabolites) were analyzed with an untargeted metabolome analysis. Studies such as these show the importance of metabolomic data in bioremediation research. Villas-Bôas and Bruheim, 2007 explored the role of metabolomics in bioremediation research and described various experimental and conceptual approaches that have been developed for metabolomics and should be applied at bioremediation studies. Tang et al. (2007) evaluated the fluxome profile of Shewanella, a marine bacterial species known to possess co-metabolic pathways for the biodegradation of toxic metals, halogenated organic compounds and radionuclides. The analysis was carried out using biochemical, GC-MS, and statistical and genetic algorithms, and their results showed that Shewanella sp. exhibits a comparatively flexible metabolism flux when subjected to various carbon sources. Durand et al. (2010) performed a metabolic analysis of Bacillus sp. to define the metabolic pathways of this bacterial strain during the degradation of the herbicide mesotrione. Their analysis, which used liquid chromatography NMR and ex situ NMR, identified a total of six metabolites, of which the structures of four metabolites were suggested. Wharfe et al. (2010) applied FT-IR to monitor the biochemical and phenotypic changes in bacterial communities that could degrade aromatic compounds (i.e., phenol) that had been released from industrial bioreactors.

\section{METAGENOMICS IN PLANT-MICROBE INTERACTIONS AND ITS SIGNIFICANCE FOR BIOREMEDIATION}

Plant-omics is one of the fastest growing fields of science, due to the urgent need to address important questions faced by humanity respecting environmental remediation, ecological sustainability, medicine, biofuels, and agriculture (Gemperline et al., 2016). Although the plant-microbe interaction has been known for many years, its impact on the plant's hardiness and production was clarified only recently. Plant-microbe associations are extremely diverse in nature, with microbes prospering and thriving within the plant structures, both underground and above ground (Vorholt, 2012; Bulgarelli et al., 2015). Environmental pollution has increased over the past two decades as a result of both natural events and anthropogenic activities (Vácha et al., 2015). The widespread contamination of ecosystems resulting from metallurgical and mining activities, and atmospheric deposition from fossil fuel power plants has led to the accumulation of harmful toxic chemicals in the environment, such as PAHs. Long-term exposure to PAHs can cause damage to the respiratory system, central nervous system, and endocrine system, and can cause skin, liver, lung, bladder, and kidney cancers (Singh et al., 2004; Locksley, 2011). Therefore, the need to remediate $\mathrm{PAH}$-contaminated environments is of great importance to protect both humans and animals. Plantassociated microbes can have phyllospheric, endophytic and rhizospheric interactions, and the interaction between these microbes and their host plants enables much of the plant growth and survivability outcomes in polluted environments. Plants can significantly improve bioremediation rates and outcomes, as they provide habitat and exchange nutrients with their microbial counterparts. In turn, the microbes improve the growth of plants by reducing the toxicity of soils via the removal of contaminants. Genome-enabled techniques offer a framework of plant-microbe interactions during environmental remediation. Metagenomic studies provide a way to unravel the plantassociated microbial diversity of the contaminated environments. This knowledge will form a basis for understanding indigenous microbial communities and will help to devise strategies for the remediation of contaminated environments (Figure 4).

\section{STANDARDIZATION IN BIOREMEDIATION TO OVERCOME OBSTACLES AND TO INCREASE AND ENHANCE PREDICTABILITY}

Globally, there are a number of environmental bioremediation sites that are undergoing in situ or ex situ bioremediation. Among these, many well-known cases involve the removal of both organic (e.g., explosives, TCE, solvents, dyes, etc.) and inorganic (e.g., nitrates, chlorides, uranium) pollutants (Nizzetto, 2010; He and McMahon, 2011). Many of these operations are not only examples for the elimination of environmental pollutants; they also function as model systems to increase our understanding of the biology within an ecosystem, including microbes, under natural conditions. In addition to the remarkable successes that are being achieved in the laboratory and, in some cases, in the environment, there have also been several failures (de Lorenzo, 2009). This demonstrates that it is not always easy to transform lab-based research to the field and that novel and pioneering attempts are necessary to increase the predictability of bioremediation results. The use of biology alone will not entirely eliminate pollution. It must be understood that successful bioremediation also requires the consideration of engineering aspects. Efforts are needed to minimize the operational start-up time and to set up fast and reliable sensors to monitor conditions that can lead to improved microbial effectiveness, when required (van der Meer and Belkin, 2010; Ramos et al., 2018).

Over the past few decades, advances in bioremediation have been largely achieved from culturable microbes that are easily obtainable and possess well-defined catalytic activities. However, much of the catabolic potential in nature remains unexplored, in part because microbiologists have not been able to replicate the very specific fundamental features $(\mathrm{pH}$, nutrients, temperature, osmotic conditions, etc.) of their environment. Currently, "omics" technologies are being exploited to discover 


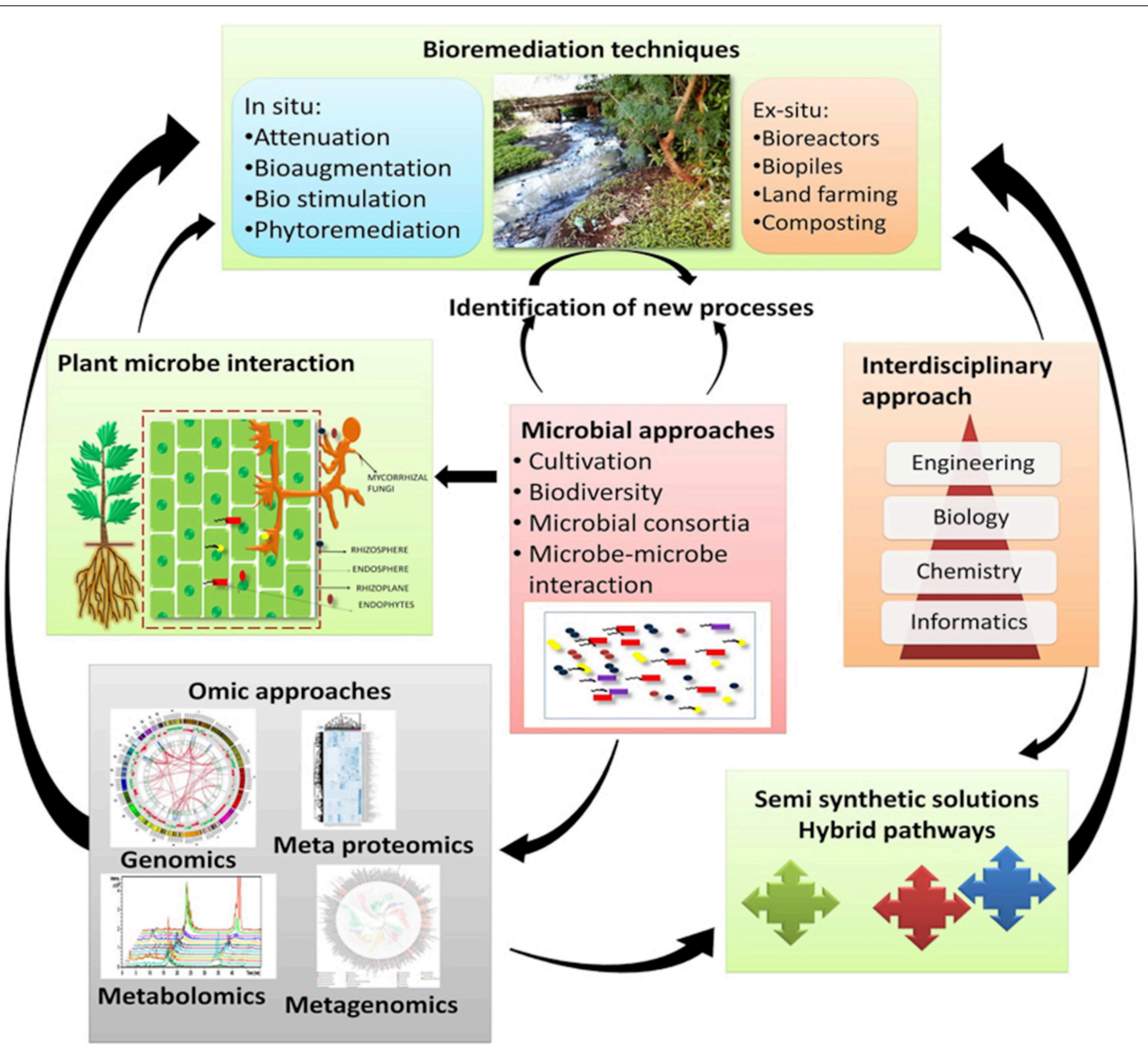

FIGURE 4 | Novel processes in order to improve bioremediation of polluted environments.

the hidden microbial potential prior to their cultivation, with the intent of rescuing enzymatic activities related to the degradation of environmental contaminants (Figure 4). Metagenomic technology has changed the way in which environmental microbiologists think, and intensive genome mining will surely allow a greater exploration of microbes that have biodegradation properties.

\section{IN SILCO ANALYSIS IN BIOREMEDIATION}

The metagenomic approaches described above have greatly increased our understanding of the physiological capabilities of microbes. However, to predict the functioning of microorganisms within an environment, a more holistic view of metabolism is required to illustrate the outcome of the thousands of individual reactions occurring simultaneously in a microbial cell. These descriptions are becoming possible due to advances in the development of in silico analyses (Cardoso et al., 2015). Bioinformatics, which has already made novel discoveries in the field of microbial ecology, is now expected to hasten the discovery of unexamined areas of the microbial universe. The data deluge has made bioinformatics an indispensable tool in modern day research; recent innovative technologies are generating a large amount of data at an unprecedented pace. The huge amount of data generated as a result of sequencing has placed high demands and burdens on computers and computational scientists. Bioinformatics relies on genomics and proteomics, and it holds great promise as a tool to address long-standing questions regarding the molecular mechanisms involved in biodegradation pathways (Fulekar, 2010). Bioinformatics has shown its novel capabilities in the field of bioremediation Bioinformatics has shown its novel capabilities in the field of bioremediation, however the resources that are devoted toward the bioremediational processes are still scarce. A number of novel and interesting projects have been carried with the aim to organize the bulk of data generated via multi-omics approaches. One prime example of such projects is "The University of Minnesota Biocatalysis/Biodegradation Database (UMBBD)" (Gao et al., 2010). Another example is "The Environmental Contaminant Biotransformation Pathway" (The enviPath tool) and was very recently launched as the updated version of EAWAGBBD/ PPS (Wicker et al., 2016). Some other prominent examples are those BioCyc and MetaCyc databases by SRI International (Caspi et al., 2016). 


\section{SUCCESS STORIES: OMICS-APPROACHES IN MICROBIAL BIOREMEDIATION}

Microbial-bioremediation is generally viewed as a sustainable and cost effective technology, as it depends on microorganisms to transform the contaminants into benign compounds. Multi-omics techniques are capable of revolutionizing the biological treatment of contaminated environments by allowing highly sensitive characterization and functioning of the yet-uncultured microorganisms. To elucidate how, different omic-approaches can be applied to microbial-mediated bioremediation applications, here in this section, we have tried to mention some of the success stories of different "omic" approaches in microbial bioremediation.

Environmental biologists deem microbial bioremediation to be one of the potent tools to eliminate environmental contaminants (Bell et al., 2014; Chemerys et al., 2014; Roling, 2015). A number of review articles have recently been published and provide a much detailed account about the role of multi-omics (metagenomics, proteomics, metatranscriptomics, metabolomics, and fluxomics) approaches in microbial bioremediation. Recently "Omics"-based techniques revitalized the study of polycyclic aromatic hydrocarbons $(\mathrm{PAH})$ catabolism by offering an integrative view regarding the biochemical processes responsible for the degradation of PAH in contaminated sites (El Amrani et al., 2015). In the past few years, a number of detailed review articles have been published based on various aspects of metagenomic approach and have highlighted its pledge for bioremediation (Sar and Islam, 2012; Bell et al., 2015; Nousiainen, 2015; Jung et al., 2016; Techtmann and Hazen, 2016; Duarte et al., 2017; Tripathi et al., 2018). Metagenomics indeed allowed the study of microbial communities within their whole complexity, including interactions among the community members. Since the complete mineralization of any pollutant requires metabolic-crosstalk between microbial communities and is hence performed by microbial consortia rather than individual species. In contrast to other bioremediational approaches (physical and chemical), metagenomic bioremediation provides the best results with better degrading ratios Recently a number of the studies have been carried that provide an insight of how proteomics help in bioremediation (Kim et al., 2003, 2004, 2007; Zhao et al., 2005). Similarly (Jennings et al., 2009) while using the integrative omicapproach of Proteomic and Transcriptomic revealed the genes that are up regulated by cisdichloroethene ( $\mathrm{CDCE})$ a suspected carcinogen in JS666 strain of Polaromonas sp. In another study (Holmes et al., 2009), while using the whole-genome microarray analysis decoded the transcriptome of Geobacter uraniireducens strain capable of growing in uranium-contaminated subsurface sediments. Many other prominent studies that discuss the importance and breakthroughs of the metatranscriptomics and proteomics in the field of microbial-mediated bioremediation are those carried out (Singh, 2006; Lee et al., 2012; Shukla, 2017; Niu et al., 2018). Now a days, it is a well-established fact that metabolome analysis serves as a potent approach for discovering novel metabolic pathways and networks (Weckwerth and Fiehn, 2002; Villas-Bôas et al., 2007). Metabolomics approach aims to quantify the functional role of the metabolites within the microbial cells via separation and analytical techniques, while as fluxomics aims at determining the metabolic fluxes. Bargiela et al. (2015), applied metabolomics techniques to three different chronically hydrocarbon (petroleum) polluted sites and revealed the importance of the general aerobic processes that were uncoupled with degradation. The results from their study showed the presence of more than 4,776 metabolite in these polluted sites, thereby revealing the high metabolic heterogeneity within the study sites. A number of other studies that have used metabolomic and fluxomics approaches to study the biodegradation of anthropogenic environmental pollutants were carried out by Villas-Bôas and Bruheim (2007), Wiechert et al. (2007), Keum et al. (2008), Tang et al. (2009), Brune and Bayer (2012).

\section{SYSTEMS BIOLOGY APPROACHES TO BIOREMEDIATION}

Nature has its ways of cleaning the environments by eliminating the contaminants in order to maintain a perfect balance; however in this modern era of industrialization the rate at which the pollutants are released into the environment has crossed the threshold limit of the nature. Recently, the modern approaches such as genomics, transcriptomics, proteomics, metabolomics, and fluxomics have been applied to the systems biology of microbial consortia with in diverse array environments. Systems biology, an integrated research approach is used to study the intricate biological systems by exploring interactions and networks at different structural levels (molecular, cellular, community, and ecosystem). Integration of the results from various "omics-approaches" has offered crucial insights into the survival, metabolism and interaction of microbial communities within their native environments (Baker and Banfield, 2003; Hemme et al., 2010; Hu et al., 2010). Systems biology approaches are continuously being adopted to unravel key processes in order to understand, predict, optimize and appraise the survival strategies, and microbial function within the ecosystems of interest. However, for this approach to be successful, it needs to overcome some challenges, including the materials and reagents, amount of samples, high cost of sample processing, technocrats to process the samples, and data synthesis (Chakraborty et al., 2012). In order to gain an understanding of intricate in situ bioremediation processes, monitoring techniques, enzyme probes, genomics, transcriptomics, proteomics, metabolomics, and metabolomics provide unique insights into the important microbial reactions. Microbes, are able to directly immobilize and detoxify toxicants (Elias et al., 2003). As discussed, the multiomics approaches have been major breach in providing much deeper insights both in the cellular function and gene products interacting within the environment (VerBerkmoes et al., 2009a). Immunomagnetic separations, a specific, efficient, rapid, and technically simple technique has been applied for the separation of the target microbes directly from microbial consortium (Chakraborty et al., 2011). The technique holds a great pledge in enabling the omic-based (proteomics, transcriptomics, metabolomics) studies directly on cells collected from the 
environment. Integrating all these techniques along with insilco analysis and modeling will enable novel break-through in the field of environmental biotechnology. Since 2004, a number of research groups all over the world have been involved in the active implementation of the basic to understand and comprehend the systems biology of contaminated environments and predicting feasible and practicable remediation technologies. Systems biology approaches have successfully been applied to various environmental contaminants, some of the notable reviews on systems biology approaches for radionuclides are (Palumbo et al., 2004; Fields et al., 2006; Cardenas et al., 2008; Conrad et al., 2010), for hydrocarbons (Harayama et al., 2004; de Lorenzo, 2008; Fredrickson et al., 2008; Atlas and Hazen, 2011; Zhou et al., 2011), for metals (Fredrickson et al., 2008; Hubbard et al., 2008; Han et al., 2010; Liu et al., 2011), and for chlorinated solvents (Song et al., 2002; Lehman et al., 2004; Erwin et al., 2005; Scow and Hicks, 2005; Rahm et al., 2006; Cupples, 2008; Illman and Alvarez, 2009; Werner et al., 2009; Conrad et al., 2010).

\section{FUTURE PERSPECTIVES}

Considering the present state of "omics," future research in microbe-based bioremediation may focus on the following:

1) Mining of the current data to provide additional insights into bioremediation pathways (mechanisms).

2) Numerical modeling and simulation of the data, which requires the advancement of novel algorithms.

3) Standardization of protocols for the collection, analysis, reposition, and transmission of data.

4) Identification and characterization of novel indicators (biomarkers). These indicators may help to determine the use of particular bioremediation operations.

5) Integration of the data generated via a number of the "omics" approaches. By integrating metagenomics (functional), transcriptomics, proteomics and metabolomic data, researchers may have a more clear and complete understanding of microbe-based bioremediation pathways and could provide a thorough and detailed perspective on the microbial consortia needed for the bioremediation process.

\section{CONCLUDING REMARKS}

Considering the immense threat posed by widespread environmental contamination by xenobiotics and other toxic chemicals, novel methods for decontamination, and clean-up are urgently required. Since, the interaction between the microbial communities and the environmental

\section{REFERENCES}

Abou Seeda, M. A., Yassen, A. A., and Abou El-Nour, E. Z. A. A. (2017). Microorganism as a tool of bioremediation technology for cleaning waste and industrial water. Biosci. Res. 14, 633-644.

Ahuti, S. (2015). Industrial growth and environmental degradation. Int. Educ. Res. J. 1, 5-7. contaminants are far from being simple, and it is challenging to understand and explore the extreme environments, these microorganisms inhabit. Environmental contamination can be viewed as an ecological malaise and for such a malaise; bioremediation can be prescribed as a "perfect medicine." Toward a much deeper perceptive and understanding of the microbial-mediated bioremediation, novel omic-approaches (genomics, transcriptomics, proteomics, metabolomics, and fluxomics) presents a remarkable pledge as tools to study the mechanisms involved in various bioremediational pathways. The integrative approach of these techniques in this era of "omics" has paved way for the successful execution of the efficient bioremediational strategies. The applications of these approaches are still in their infancy; but the bulk of data that is constantly being generated by the present day omic technocrats needs to be organized within the informative databases. Omicsapproaches show great ability to predict organism's metabolism in polluted environments and to envisage the microbialmediated attenuation of the pollutants to fasten bioremediation. The study of molecular mechanisms behind the microbial transformations of the toxic pollutants using omic-approaches to bioremediation would aid in tracking the responsible organisms and in efficient elimination of the contaminants from the environments.

\section{AUTHOR CONTRIBUTIONS}

MM prepared the draft of manuscript under the guidance of AK and SY. AD prepared the illustrations. EA and AH edited the manuscript.

\section{ACKNOWLEDGMENTS}

MM (Y15465008) would like to acknowledge the University Ph.D. Fellowship for supporting this study. AD would like to acknowledge the Department of Science and Technology, New Delhi, India for providing financial support through the DST Inspire Ph.D. Fellowship (IF160797). The authors would like to extend their sincere appreciation to the Deanship of Scientific Research at King Saud University for its funding of the research group number (RG1435-014).

\section{SUPPLEMENTARY MATERIAL}

The Supplementary Material for this article can be found online at: https://www.frontiersin.org/articles/10.3389/fmicb. 2018.01132/full\#supplementary-material

Angelim, A. L., Costa, S. P., Farias, B. C. S., Aquino, L. F., and Melo, V. M. M. (2013). An innovative bioremediation strategy using a bacterial consortium entrapped in chitosan beads. J. Environ. Manage. 127, 10-17. doi: 10.1016/j.jenvman.2013.04.014

Armougom, F., and Raoult, D. (2009). Exploring microbial diversity using $16 \mathrm{~S}$ rRNA high-throughput methods. J. Comput. Sci. Syst. Biol. 2, 74-92. doi: $10.4172 /$ jcsb.1000019 
Atlas, R. M., and Hazen, T. C. (2011). Oil biodegradation and bioremediation: a tale of the two worst spills in US history. Environ. Sci. Technol. 45, 6709-6715. doi: 10.1021/es2013227

Baker, B. J., and Banfield, J. F. (2003). Microbial communities in acid mine drainage. FEMS Microbiol. Ecol. 44, 139-152. doi: 10.1016/S0168-6496(03)00028-X

Bargiela, R., Herbst, F. A., Martínez-Martínez, M., Seifert, J., Rojo, D., Cappello, S., et al. (2015). Metaproteomics and metabolomics analyses of chronically petroleum-polluted sites reveal the importance of general anaerobic processes uncoupled with degradation. Proteomics 15, 3508-3520. doi: 10.1002/pmic.201400614

Bedard, D. L., Bailey, J. J., Reiss, B. L., and Jerzak, G. V. (2006). Development and characterization of stable sediment-free anaerobic bacterial enrichment cultures that dechlorinate aroclor 1260. Appl. Environ. Microbiol. 72, 2460--2470. doi: 10.1128/AEM.72.4.2460-24 70.2006

Bell, T. H., Greer, C. W., and Yergeau, E. (2015). "Metagenomics potential for bioremediation," in Encyclopedia of Metagenomics: Genes, Genomes and Metagenomes: Basics, Methods, Databases and Tools, ed K. E. Nelson (Boston, MA: Springer), 429-439.

Bell, T. H., Joly, S., Pitre, F. E., and Yergeau, E. (2014). Increasing phytoremediation efficiency and reliability using novel omics approaches. Trends Biotechnol. 32, 271-280. doi: 10.1016/j.tibtech.2014.02.008

Benndorf, D., Balcke, G. U., Harms, H., and von Bergen, M. (2007). Functional metaproteome analysis of protein extracts from contaminated soil and groundwater. ISME J. 1, 224-234. doi: 10.1038/ismej.2007.39

Bringel, F., Postema, C. P., Mangenot, S., Bibi-Triki, S., Chaignaud, P., Farhan Ul Haque, M., et al. (2017). Genome sequence of the dichloromethane-degrading bacterium Hyphomicrobium sp. strain GJ21. Genome Announc. 5:e00622-17. doi: 10.1128/genomeA.00622-17

Brune, K. D., and Bayer, T. S. (2012). Engineering microbial consortia to enhance biomining and bioremediation. Front. Microbiol. 3:203. doi: $10.3389 /$ fmicb. 2012.00203

Bulgarelli, D., Garrido-Oter, R., Münch, P. C., Weiman, A., Dröge, J., Pan, Y., et al. (2015). Structure and function of the bacterial root microbiota in wild and domesticated barley. Cell Host Microbe 17, 392-403. doi: 10.1016/j.chom.2015.01.011

Bursle, E., and Robson, J. (2016). Non-culture methods for detecting infection. Aust. Prescr. 39, 171-175. doi: 10.18773/austprescr.2016.059

Cardenas, E., Wu, W. M., Leigh, M. B., Carley, J., Carroll, S., Gentry, T., et al. (2008). Microbial communities in contaminated sediments, associated with bioremediation of uranium to submicromolar levels. Appl. Environ. Microbiol. 74, 3718-3729. doi: 10.1128/AEM.02308-07

Cardoso, J. G., Andersen, M. R., Herrgård, M. J., and Sonnenschein, N. (2015). Analysis of genetic variation and potential applications in genome-scale metabolic modeling. Front. Bioeng. Biotechnol. 3:13. doi: $10.3389 /$ fbioe. 2015.00013

Carroll, K. C., and Patel, R. (2015). "Systems for identification of bacteria and fungi," in Manual of Clinical Microbiology, 11th Edn, eds J. H. Jorgensen, M. A. Pfaller, K. C. Carroll, G. Funke, M. L. Landry, S. S. Richter, et al. (Washington, DC: American Society of Microbiology), 29-43.

Caspi, R., Billington, R., Ferrer, L., Foerster, H., Fulcher, C. A., Keseler, I. M., et al. (2016). The MetaCyc database of metabolic pathways and enzymes and the BioCyc collection of pathway/genome databases. Nucleic Acids Res. 44, D471-D480. doi: 10.1093/nar/gkv1164

Chakraborty, R., Hazen, T. C., Joyner, D. C., Küsel, K., Singer, M. E., Sitte, J., et al. (2011). Use of immunomagnetic separation for the detection of Desulfovibrio vulgaris from environmental samples. J. Microbiol. Methods 86, 204-209. doi: 10.1016/j.mimet.2011.05.005

Chakraborty, R., Wu, C. H., and Hazen, T. C. (2012). Systems biology approach to bioremediation. Curr. Opin. Biotechnol. 23, 483-490. doi: 10.1016/j.copbio.2012.01.015

Chandran, P., and Das, N. (2011). Characterization of sophorolipid biosurfactant. Int. J. Sci. Nat. 2, 63-71.

Chauhan, A., Fazlurrahman., Oakeshott, J. G., and Jain, R. K. (2008). Bacterial metabolism of polycyclic aromatic hydrocarbons: strategies for bioremediation. Ind. J. Microbiol. 48, 95-113. doi: 10.1007/s12088-0080010-9
Chemerys, A., Pelletier, E., Cruaud, C., Martin, F., Violet, F., and Jouanneaua Y. (2014). Characterization of novel polycyclic aromatic hydrocarbon dioxygenases from the bacterial metagenomic DNA of a contaminated soil. Appl. Environ. Microbiol. 80, 6591-6600. doi: 10.1128/AEM.0 1883-14

Chistoserdova, L. (2017). Application of omics approaches to studying methylotrophs and methylotroph comunities. Curr. Issues Mol. Biol. 24, 119-142. doi: 10.21775/cimb.024.119

Conrad, M. E., Brodie, E. L., Radtke, C. W., Bill, M., Delwiche, M. E., Lee, M. H et al. (2010). Field evidence for co-metabolism of trichloroethene stimulated by addition of electron donor to groundwater. Environ. Sci. Technol. 44 4697-4704. doi: 10.1021/es903535j

Corretto, E., Antonielli, L., Sessitsch, A., Kidd, P., Weyens, N., and Brader, G. (2015). Draft genome sequences of 10 Microbacterium spp., with emphasis on heavy metal-contaminated environments. Genome Announc. 3:e00432-15. doi: 10.1128/genomeA.00432-15

Cupples, A. M. (2008). Real-time PCR quantification of Dehalococcoides populations: methods and applications. J. Microbiol. Methods 72, 1-11. doi: 10.1016/j.mimet.2007.11.005

Czaplicki, L. M., and Gunsch, C. K. (2016). Reflection on molecular approaches influencing state-of-the-art bioremediation design: culturing to microbial community fingerprinting to omics. J. Environ. Eng. 142:03116002-1-13. doi: 10.1061/(ASCE)EE.1943-7870.0001141

Dadhwal, M., Singh, A., Prakash, O., Gupta, S. K., Kumari, K., Sharma, P., et al. (2009). Proposal of biostimulation for hexachlorocyclohexane ( $\mathrm{HCH}$ )decontamination and characterization of culturable bacterial community from high-dose point HCH-contaminated soils. J. Appl. Microbiol. 106, 381-392. doi: $10.1111 / j .1365-2672.2008 .03982 . x$

Daniel, R. (2005). The metagenomics of soil. Nat. Rev. Microbiol. 3, 470-478. doi: $10.1038 /$ nrmicrol160

Dash, H. R., and Das, S. (2012). Bioremediation of mercury and the importance of bacterial mer genes. Int. Biodeterior. Biodegrad. 75, 207-213. doi: 10.1016/j.ibiod.2012.07.023

DeLong, E. F. (2005). Microbial community genomics in the ocean. Nat. Rev. Microbiol. 3, 459-469. doi: 10.1038/nrmicro1158

DeLong, E. F., Preston, C. M., Mincer, T., Rich, V., Hallam, S. J., Frigaard, N. U., et al. (2006). Community genomics among stratified microbial assemblages in the ocean's interior. Science 311, 496-503. doi: 10.1126/science.1120250

de Lorenzo, V. (2008). Systems biology approaches to bioremediation. Curr. Opin. Biotechnol. 19, 579-589. doi: 10.1016/j.copbio.2008.10.004

de Lorenzo, V. (2009). Recombinant bacteria for environmental release : what went wrong and what we have learnt from it. Clin. Microbiol. Infect. 15(Suppl. 1). 63-65. doi: 10.1111/j.1469-0691.2008.02683.x

Desai, C., Pathak, H., and Madamwar, D. (2010). Advances in molecular and "-omics" technologies to gauge microbial communities and bioremediation at xenobiotic/anthropogen contaminated sites. Bioresour. Technol. 101, 1558-1569. doi: 10.1016/j.biortech.2009.10.080

Dickson, R. P., Erb-Downward, J. R., Prescott, H. C., Martinez, F. J., Curtis, J. L., Lama, V. N., et al. (2014). Analysis of culture-dependent versus culture-independent techniques for identification of bacteria in clinically obtained bronchoalveolar lavage fluid. J. Clin. Microbiol. 52, 3605-3613. doi: 10.1128/JCM.01028-14

Doré, J., Perraud, M., Dieryckx, C., Kohler, A., Morin, E., Henrissat, B., et al. (2015). Comparative genomics, proteomics and transcriptomics give new insight into the exoproteome of the basidiomycete Hebeloma cylindrosporum and its involvement in ectomycorrhizal symbiosis. New Phytol. 208, 1169-1187. doi: $10.1111 /$ nph.13546

Duarte, M., Nielsen, A., Camarinha-Silva, A., Vilchez-Vargas, R., Bruls, T., Wos-Oxley, M. L., et al. (2017). Functional soil metagenomics: elucidation of polycyclic aromatic hydrocarbon degradation potential following 12 years of in situ bioremediation. Environ. Microbiol. 19, 2992-3011. doi: 10.1111/1462-2920.13756

Durand, S., Sancelme, M., Besse-Hoggan, P., and Combourieu, B. (2010). Biodegradation pathway of mesotrione: complementarities of NMR, LC-NMR and LC-MS for qualitative and quantitative metabolic profiling. Chemosphere 81, 372-380. doi: 10.1016/j.chemosphere.2010.07.017

Ebn, S., Kühner, S., Wöhlbrand, L., Fritz, I., Wruck, W., Hultschig, C., et al. (2005). Substrate-dependent regulation of anaerobic degradation pathways for 
toluene and ethylbenzene in a denitrifying substrate-dependent regulation of anaerobic degradation pathways for toluene and ethylbenzene in a denitrifying bacterium. J. Bacteriol. 187, 1493-1503. doi: 10.1128/JB.187.4.14931503.2005

El Amrani, A., Dumas, A. S., Wick, L. Y., Yergeau, E., and Berthomé, R. (2015). "Omics" insights into PAH degradation toward improved green remediation biotechnologies. Environ. Sci. Technol. 49, 11281-11291. doi: 10.1021/acs.est.5b01740

Elias, D. A., Krumholz, L. R., Wong, D., Long, P. E., and Suflita, J. M. (2003). Characterization of microbial activities and U reduction in a shallow aquifer contaminated by uranium mill tailings. Microb. Ecol. 46, 83-91. doi: 10.1007/s00248-002-1060-x

Erwin, D. P., Erickson, I. K., Delwiche, M. E., Colwell, F. S., Strap, J. L., and Crawford, R. L. (2005). Diversity of oxygenase genes from methane-and ammonia-oxidizing bacteria in the Eastern Snake River Plain aquifer. Appl. Environ. Microbiol. 71, 2016-2025. doi: 10.1128/AEM.71.4.2016-2025.2005

Fakruddin, M., and Mannan, K. (2013). Methods for analyzing diversity of microbial communities in natural environments. Ceylon J. Sci. 42, 19-33. doi: 10.4038/cjsbs.v42i1.5896

Fields, M. W., Bagwell, C. E., Carroll, S. L., Yan, T., Liu, X., Watson, D. B., et al. (2006). Phylogenetic and functional biomakers as indicators of bacterial community responses to mixed-waste contamination. Environ. Sci. Technol. 40, 2601-2607. doi: 10.1021/es051748q

Fredrickson, J. K., Romine, M. F., Beliaev, A. S., Auchtung, J. M., Driscoll, M. E., Gardner, T. S., et al. (2008). Towards environmental systems biology of Shewanella. Nat. Rev. Microbiol. 6, 592-603. doi: 10.1038/nrmicro1947

Fulekar, M. H. (2010). Environmental Biotechnology. Mumbai: Taylor \& Francis.

Gafan, G. P., and Spratt, D. A. (2005). Denaturing gradient gel electrophoresis gel expansion (DGGEGE) - an attempt to resolve the limitations of co-migration in the DGGE of complex polymicrobial communities. FEMS Microbiol. Lett. 253, 303-307. doi: 10.1016/j.femsle.2005.09.048

Gao, J., Ellis, L. B. M., and Wackett, L. P. (2010). The university of minnesota biocatalysis/biodegradation database: improving public access. Nucl. Acids Res. 38, D488-D491. doi: 10.1093/nar/gkp771

Garbeva, P., Van Veen, J. A., and van Elsas, J. (2004). Microbial diversity in soil: selection of microbial populations by plant and soil type and implications for disease suppressiveness. Annu. Rev. Phytopathol. 42, 243-270. doi: 10.1146/annurev.phyto.42.012604.135455

Gemperline, E., Keller, C., and Li, L. (2016). Mass spectrometry in plant-omics. Anal. Chem. 88, 3422-3434. doi: 10.1021/acs.analchem.5b02938

George, I. F., Bouhajja, E., and Agathos, S. N. (2011). 6.06 - Metagenomics for Bioremediation. 2nd Edn. Elsevier B.V.

Gill, S., Pop, M. T., Deboy, R., Eckburg, P., Turnbaugh, P., Samuel, B., et al. (2006). Metagenomic analysis of the human distal gut microbiome. Science 312, 1355-1359. doi: 10.1126/science. 1124234

Gkorezis, P., Bottos, E. M., Van Hamme, D. J., Thijs, S., Rineau, F., Franzetti, A., et al. (2015). Draft genome sequence of arthrobacter sp. strain SPG23, a hydrocarbon-degrading and plant growth-promoting soil bacterium. Genome Announc. 3, e01517-e01515. doi: 10.1128/genomeA.01517-15

Green, S. J., Leigh, M. B., and Neufeld, J. D. (2010). "Denaturing gradient gel electrophoresis (DGGE) for microbial community analysis," in Handbook of Hydrocarbon and Lipid Microbiology, ed K. N. Timmis (Berlin; Heidelberg: Springer), 4137-4158.

Griggs, D., Stafford-Smith, M., Gaffney, O., Rockström, J., Öhman, M. C., Shyamsundar, P., et al. (2013). Policy: sustainable development goals for people and planet. Nature 495, 305-307. doi: 10.1038/495305a

Han, R., Geller, J. T., Yang, L., Brodie, E. L., Chakraborty, R., Larsen, J. T., et al. (2010). Physiological and transcriptional studies of $\mathrm{Cr}$ (VI) reduction under aerobic and denitrifying conditions by an aquifer-derived pseudomonad. Environ. Sci. Technol. 44, 7491-7497. doi: 10.1021/es10 $1152 \mathrm{r}$

Handelsman, J., Rondon, M. R., Brady, S. F., Clardy, J., and Goodman, R. M. (1998). Molecular biological access to the chemistry of unknown soil microbes: a new frontier for natural products. Chem. Biol. 5, R245-R249. doi: 10.1016/S1074-5521(98)90108-9

Harayama, S., Kasai, Y., and Hara, A. (2004). Microbial communities in oil-contaminated seawater. Curr. Opin. Biotechnol. 15, 205-214. doi: 10.1016/j.copbio.2004.04.002
Hauptmann, A. L., Sicheritz-Pontén, T., Cameron, K. A., Bælum, J., Plichta, D. R., Dalgaard, M., et al. (2017). Contamination of the Arctic reflected in microbial metagenomes from the Greenland ice sheet. Environ. Res. Lett. 12:074019. doi: 10.1088/1748-9326/aa7445

He, S., and McMahon, K. D. (2011). Microbiology of "Candidatus Accumulibacter" in activated sludge. Microb. Biotechnol. 4, 603-619. doi: 10.1111/j.1751-7915.2011.00248.x

He, Y., Wei, K., Si, K., Mathieu, J., Li, M., and Alvarez, P. J. J. (2017). Whole-genome sequence of the 1, 4-dioxane-degrading bacterium Mycobacterium dioxanotrophicus PH-06. Genome Announc. 5:e00625-17. doi: 10.1128/genomeA.00625-17

Head, I. M., Singleton, I., and Milner, M. G. (2003). Bioremediation: A Critical Review. Horizon Scientific.

Hemme, C. L., Deng, Y., Gentry, T. J., Fields, M. W., Wu, L., Barua, S., et al. (2010). Metagenomic insights into evolution of a heavy metalcontaminated groundwater microbial community. ISME J. 4, 660-672. doi: 10.1038/ismej.2009.154

Holmes, D. E., O’Neil, R. A., Chavan, M. A., N'Guessan, L. A., Vrionis, H. A., Perpetua, L. A., et al. (2009). Transcriptome of Geobacter uraniireducens growing in uranium-contaminated subsurface sediments. ISME J. 3, 216-230. doi: 10.1038 /ismej.2008.89

Hu, Y., Fu, C., Yin, Y., Cheng, G., Lei, F., Yang, X., et al. (2010). Construction and preliminary analysis of a deep-sea sediment metagenomic fosmid library from qiongdongnan basin, south china sea. Mar. Biotechnol. 12, 719-727. doi: 10.1007/s10126-010-9259-1

Hubbard, S. S., Williams, K., Conrad, M. E., Faybishenko, B., Peterson, J., Chen, J., et al. (2008). Geophysical monitoring of hydrological and biogeochemical transformations associated with $\mathrm{Cr}(\mathrm{VI})$ bioremediation. Environ. Sci. Technol. 42, 3757-3765. doi: 10.1021/es071702s

Hwang, C., Copeland, A., Lucas, S., Lapidus, A., Barry, K., Detter, J. C., et al. (2016). Complete genome sequence of Alkaliphilus metalliredigens strain QYMF, an alkaliphilic and metal-reducing bacterium isolated from borax-contaminated leachate ponds. Genome Announc. 4:e01226-6. doi: 10.1128/genomeA.01226-16

Illman, W. A., and Alvarez, P. J. (2009). Performance assessment of bioremediation and natural attenuation. Crit. Rev. Environ. Sci. Technol. 39, 209-270. doi: $10.1080 / 10643380701413385$

Jørgensen, K. S. (2007). In situ bioremediation. Adv. Appl. Microbiol. 61, 285-305. doi: 10.1016/S0065-2164(06)61008-3

Jennings, L. K., Chartrand, M. M. G., Lacrampe-Couloume, G., Lollar, B. S., Spain, J. C., and Gossett, J. M. (2009). Proteomic and transcriptomic analyses reveal genes upregulated by cis-dichloroethene in Polaromonas sp. strain JS666. Appl. Environ. Microbiol. 75, 3733-3744. doi: 10.1128/AEM. 00031-09

Joshi, M. N., Dhebar, S. V., Bhargava, P., Pandit, A. S., Patel, R. P., Saxena, A. K., et al. (2014). Metagenomic approach for understanding microbial population from petroleum muck. Genome Announc. 2:e00533-14. doi: 10.1128/genomeA.00533-14

Ju, F., and Zhang, T. (2015). $16 \mathrm{~S}$ rRNA gene high-throughput sequencing data mining of microbial diversity and interactions. Appl. Microbiol. Biotechnol. 99, 4119-4129. doi: 10.1007/s00253-015-6536-y

Junca, H., and Pieper, D. H. (2004). Functional gene diversity analysis in BTEX contaminated soils by means of PCR-SSCP DNA fingerprinting: comparative diversity assessment against bacterial isolates and PCR-DNA clone libraries. Environ. Microbiol. 6, 95-110. doi: 10.1046/j.1462-2920.2003. 00541.x

Jung, J., Philippot, L., and Park, W. (2016). Metagenomic and functional analyses of the consequences of reduction of bacterial diversity on soil functions and bioremediation in diesel-contaminated microcosms. Sci. Rep. 6, 1-10. doi: $10.1038 /$ srep 23012

Keum, Y. S., Seo, J. S., Li, Q. X., and Kim, J. H. (2008). Comparative metabolomic analysis of Sinorhizobium sp. C4 during the degradation of phenanthrene. Appl. Microbiol. Biotechnol. 80, 863-872. doi: 10.1007/s00253-008$1581-4$

Kim, S. I., Song, S.-Y., Kim, K.-W., Ho, E.-M., and Oh, K.-H. (2003). Proteomic analysis of the benzoate degradation pathway in Acinetobacter sp. KS-1. Res. Microbiol. 154, 697-703. doi: 10.1016/j.resmic.2003. 09.003 
Kim, S.-J., Kweon, O., Jones, R. C., Freeman, J. P., Edmondson, R. D., and Cerniglia, C. E. (2007). Complete and integrated pyrene degradation pathway in Mycobacterium vanbaalenii PYR-1 based on systems biology. J. Bacteriol. 189, 464-472. doi: 10.1128/JB.01310-06

Kim, S., Jones, R. C., Cha, C., Kweon, O., Edmondson, R. D., and Cerniglia, C. E. (2004). Identification of proteins induced by polycyclic aromatic hydrocarbon in Mycobacterium vanbaalenii PYR-1 using two-dimensional polyacrylamide gel electrophoresis and de novo sequencing methods. Proteomics 4, 3899-3908. doi: 10.1002/pmic.200400872

Konopka, A., and Wilkins, M. (2012). Application of meta-transcriptomics andproteomics to analysis of in situ physiological state. Front. Microbiol. 3:184. doi: $10.3389 /$ fmicb. 2012.00184

Kosaric, N. (2001). Biosurfactants and their applications for soil bioremediation. Food Technol. Biotechnol. 39, 295-304.

Kotoky, R., Singha, L. P., and Pandey, P. (2017). Draft genome sequence of polyaromatic hydrocarbon-degrading bacterium Bacillus subtilis sr1, which has plant growth-promoting attributes. Genome Announc. 5:e01339-17. doi: 10.1128/genomeA.01339-17

Kumar, A., Chanderman, A., Makolomakwa, M., Perumal, K., and Singh, S. (2016). Microbial production of phytases for combating environmental phosphate pollution and other diverse applications. Crit. Rev. Environ. Sci. Technol. 46, 556-591. doi: 10.1080/10643389.2015.1131562

Kumavath, R. N., and Deverapalli, P. (2013). Scientific swift in bioremediation: an overview. Int. J. Pharm. Pharm. Sci. 4, 375-388. doi: 10.5772/56409

Lacerda, C. M. R., Choe, L. H., and Reardon, K. F. (2007). Metaproteomic analysis of a bacterial community response to cadmium exposure. J. Proteome Res. 6, 1145-1152. doi: 10.1021/pr060477v

Lacerda, C. M. R., and Reardon, K. F. (2009). Environmental proteomics: applications of proteome profiling in environmental microbiology and biotechnology. Brief. Funct. Genomic Proteomic 8, 75-87. doi: 10.1093/bfgp/elp005

Lam, K. N., Cheng, J., Engel, K., Neufeld, J. D., and Charles, T. C. (2015). Current and future resources for functional metagenomics. Front. Microbiol. 6:1196. doi: $10.3389 /$ fmicb.2015.01196

Lee, P. K. H., Dill, B. D., Louie, T. S., Shah, M., VerBerkmoes, N. C., Andersen, G. L., et al. (2012). Global transcriptomic and proteomic responses of dehalococcoides ethenogenes strain 195 to fixed nitrogen limitation. Appl. Environ. Microbiol. 78, 1424-1436. doi: 10.1128/AEM.06792-11

Lee, S.-Y., Kim, S. H., Lee, D.-G., Shin, S., Yun, S. H., Choi, C.-W., et al. (2014). Draft genome sequence of petroleum oil-degrading marine bacterium Pseudomonas taeanensis strain MS-3, isolated from a crude oil-contaminated seashore. Genome Announc. 2, e00818-13. doi: 10.1128/genomeA. 00818-13

Lehman, R. M., O'Connell, S. P., Banta, A., Fredrickson, J. K., Reysenbach, A.-L., Kieft, T. L., et al. (2004). Microbiological comparison of core and groundwater samples collected from a fractured basalt aquifer with that of dialysis chambers incubated in situ. Geomicrobiol. J. 21, 169-182. doi: 10.1080/01490450490275848

Liu, P., Meagher, R. J., Light, Y. K., Yilmaz, S., Chakraborty, R., Arkin, A. P., et al. (2011). Microfluidic fluorescence in situ hybridization and flow cytometry ( $\mu$ FlowFISH). Lab Chip 11, 2673-2679. doi: 10.1039/c1lc20151d

Locksley, R. M. (2011). Asthma and allergic inflammation. Immunology 140, 777-783. doi: 10.1016/j.cell.2010.03.004

Lovley, D. R. (2003). Cleaning up with genomics: applying molecular biology to bioremediation. Nat. Rev. Microbiol. 1, 35-44. doi: 10.1038/nrmicro731

Lovley, D. R., Phillips, E. J. P., Gorby, Y. A., and Landa, E. R. (1991). Microbial reduction of uranium. Nature 350, 413-416. doi: 10.1038/350413a0

Lumactud, R., Fulthorpe, R., Sentchilo, V., and van der Meer, J. R. (2017). Draft genome sequence of Plantibacter flavus strain 251 isolated from a plant growing in a chronically hydrocarbon-contaminated site. Genome Announc. 5:e027617. doi: 10.1128/genomeA.00276-17

Luo, J., Bai, Y., Liang, J., and Qu, J. (2014). Metagenomic approach reveals variation of microbes with arsenic and antimony metabolism genes from highly contaminated soil. PLoS ONE 9:e108185. doi: 10.1371/journal.pone.0108185

Maphosa, F., de Vos, W. M., and Smidt, H. (2010). Exploiting the ecogenomics toolbox for environmental diagnostics of organohalide-respiring bacteria. Trends Biotechnol. 28, 308-316. doi: 10.1016/j.tibtech.2010.03.005
Mazaheri Assadi, M., and Tabatabaee, M. S. (2010). Biosurfactants and their use in upgrading petroleum vacuum distillation residue: a review. Int. J. Environ. Res. 4, 549-572. doi: 10.22059/ijer.2010.242

Mgbemene, C. A., Nnaji, C. C., and Nwozor, C. (2016). Industrialization and its backlash: focus on climate change and its consequences. J. Environ. Sci. Technol. 9, 301-316. doi: 10.3923/jest.2016.301.316

Morales, M., Sentchilo, V., Bertelli, C., Komljenovic, A., KryuchkovcMostacci, N., Bourdilloud, A., et al. (2016). The genome of the toluene-degrading Pseudomonas veronii strain 1YdBTEX2 and its differential gene expression in contaminated sand. PLOS ONE 11:e0165850. doi: 10.1371/journal.pone.0165850

Moreno-Forero, S. K., Rojas, E., Beggah, S., and van der Meer, J. R. (2016) Comparison of differential gene expression to water stress among bacteria with relevant pollutant-degradation properties. Environ. Microbiol. Rep. 8, 91-102. doi: 10.1111/1758-2229.12356

Morris, C. E., Sands, D. C., Bardin, M., Jaenicke, R., Vogel, B., Leyronas, C. et al. (2011). Microbiology and atmospheric processes: research challenges concerning the impact of airborne micro-organisms on the atmosphere and climate. Biogeosciences 8, 17-25. doi: 10.5194/bg-8-17-2011

Mukherjee, A., Chettri, B., Langpoklakpam, J. S., Basak, P., Prasad, A., Mukherjee, A. K., et al. (2017). Bioinformatic approaches including predictive metagenomic profiling reveal characteristics of bacterial response to petroleum hydrocarbon contamination in diverse environments. Sci. Rep. 7, 1-22. doi: 10.1038/s41598-017-01126-3

Mukred, A. M., Hamid, A. A., Hamzah, A., and Yusoff, W. M. W. (2008). Development of three bacteria consortium for the bioremediation of crude petroleum-oil in contaminated water. Online J. Biol. Sci. 8, 73-79. doi: 10.3844/ojbsci.2008.73.79

Nicolaisen, M. H., Baelum, J., Jacobsen, C. S., and Sorensen, J. (2008). Transcription dynamics of the functional tfdA gene during MCPA herbicide degradation by Cupriavidus necator AEO106 (pRO101) in agricultural soil. Environ. Microbiol. 10, 571-579. doi: 10.1111/j.1462-2920.2007. 01476.x

Nishimura, Y., Kenzaka, T., Sueyoshi, A., Li, P., Fujiyama, H., Baba, T., et al. (2010). Similarity of bacterial community structure between Asian dust and its sources determined by rRNA gene-targeted approaches. Microbes Environ. 25, 22-27. doi: 10.1264/jsme2.ME09166

Niu, H., Wang, J., Zhuang, W., Liu, D., Chen, Y., Zhu, C., et al. (2018). Comparative transcriptomic and proteomic analysis of Arthrobacter sp. CGMCC 3584 responding to dissolved oxygen for cAMP production. Sci. Rep. 8, 1-13. doi: 10.1038/s41598-017-18889-4

Nizzetto, L. I. (2010). Past, present, and future controls on levels of persistent organic pollutants in the global environment. Environ. Sci Technol. 44, 6526-6531. doi: 10.1021/es100178f

Nousiainen, A. (2015). Application of Genomic Tools in Bioremediation of Atrazine Contaminated Soil and Groundwater. Dissertation, Department of Food and Environmental Sciences Faculty of Agriculture and Forestry University of Helsinki.

Ortet, P., Gallois, N., Piette, L., Long, J., Berthomieu, C., Armengaud, J. et al. (2017). Crossm draft genome sequence of bacterium isolated from chernobyl radionuclide-contaminated soil. Genome Announc. 5, 18-19. doi: 10.1128/genomeA.00092-17

Pacwa-Płociniczak, M., Płaza, G. A., Piotrowska-Seget, Z., and Cameotra, S. S. (2011). Environmental applications of biosurfactants: recent advances. Int. J. Mol. Sci. 12, 633-654. doi: 10.3390/ijms12010633

Palumbo, A. V., Schryver, J. C., Fields, M. W., Bagwell, C. E., Zhou, J.-Z., Yan, T., et al. (2004). Coupling of functional gene diversity and geochemical data from environmental samples. Appl. Environ. Microbiol. 70, 6525-6534. doi: 10.1128/AEM.70.11.6525-6534.2004

Pessoa-Filho, M., Barreto, C. C., dos Reis Junior, F. B., Fragoso, R. R., Costa, F. S., de Carvalho Mendes, I., et al. (2015). Microbiological functioning, diversity, and structure of bacterial communities in ultramafic soils from a tropical savanna. Antonie van Leeuwenhoek 107, 935-949. doi: 10.1007/s10482-015$0386-6$

Pineda, A., Kaplan, I., and Bezemer, T. M. (2017). Steering soil microbiomes to suppress aboveground insect pests. Trends Plant Sci. 22, 770-778. doi: 10.1016/j.tplants.2017.07.002 
Poretsky, R., and Ann Moran, M. (2011). Comparative day/night metatranscriptomic analysis of microbial communities in the north pacific subtropical gyre. Environ. Microbiol. 11, 1358-1375. doi: 10.1111/j.1462-2920.2008.01863.x

Prakash, D., Gabani, P., Chandel, A. K., Ronen, Z., and Singh, O. V. (2013). Bioremediation: a genuine technology to remediate radionuclides from the environment. Microb. Biotechnol. 6, 349-360. doi: 10.1111/1751-7915.12059

Prakash, T., and Taylor, T. (2012). Functional assignment of metagenomic data: challenges and applications. Brief. Bioinform. 13, 711-727. doi: 10.1093/bib/bbs033

Pushpanathan, M., Jayashree, S., Gunasekaran, P., and Rajendhran, J. (2014). Microbial Bioremediation. Elsevier Inc.

Raghunandan, K., Kumar, A., Kumar, S., Permaul, K., and Singh, S. (2018). Production of gellan gum, an exopolysaccharide, from biodiesel-derived waste glycerol by Sphingomonas spp. 3Biotech 8:71. doi: 10.1007/s13205-018-1096-3

Raghunandan, K., McHunu, S., Kumar, A., Kumar, K. S., Govender, A., Permaul, K., et al. (2014). Biodegradation of glycerol using bacterial isolates from soil under aerobic conditions. J. Environ. Sci. Heal. A Tox. Hazard. Subst. Environ. Eng. 49, 85-92. doi: 10.1080/10934529.2013.824733

Rahm, B. G., Chauhan, S., Holmes, V. F., Macbeth, T. W., Kent, S, Jr., and Alvarez-Cohen, L. (2006). Molecular characterization of microbial populations at two sites with differing reductive dechlorination abilities. Biodegradation 17, 523-534. doi: 10.1007/s10532-005-9023-9

Rahman, A., Nahar, N., Jass, J., Olsson, B., and Mandal, A. (2016). Complete genome sequence of Lysinibacillus sphaericus B1-CDA, a bacterium that accumulates arsenic. Genome Announc. 4:e00999-15. doi: 10.1128/genomeA.00999-15

Raman, G., Sakthivel, N., and Park, S. (2015). Draft genome sequence of a novel nicotine-degrading bacterium, Pseudomonas plecoglossicida TND35. Genome Announc. 3:e01162-14. doi: 10.1128/genomeA.01162-14

Ramos, J.-L., Marqués, S., van Dillewijn, P., Espinosa-Urgel, M., Segura, A., Duque, E., et al. (2018). Laboratory research aimed at closing the gaps in microbial bioremediation. Trends Biotechnol. 29, 641-647. doi: 10.1016/j.tibtech.2011.06.007

Riesenfeld, C. S., Schloss, P. D., and Handelsman, J. (2004). Metagenomics: genomic analysis of microbial communities. Annu. Rev. Genet. 38, 525-552. doi: 10.1146/annurev.genet.38.072902.091216

Roling, W. F. M. (2015). Maths on microbes: adding microbial ecophysiology to metagenomics. Microb. Biotechnol. 8, 21-22. doi: 10.1111/1751-7915.12233

Saharan, B. S., Sahu, R. K., and Sharma, D. (2012). A review on biosurfactants: fermentation, current developments and perspectives. Genet. Eng. Biotechnol. J. 2011, 1-14. Available online at: http://astonjournals.com/manuscripts/ Accepted/GEBJ-29acc7-11-11.pdf

Santos, P. M., Benndorf, D., and Sá-Correia, I. (2004). Insights into Pseudomonas putida KT2440 response to phenol-induced stress by quantitative proteomics. Proteomics 4, 2640-2652. doi: 10.1002/pmic.200300793

Sar, P., and Islam, E. (2012). "Metagenomic approaches in microbial bioremediation of metals and radionuclides," in Microorganisms in Environmental Management, eds T. Satyanarayana, B. N. Johri, A. Prakash (Springer), 525-546.

Satokari, R. M., Vaughan, E. E., Akkermans, A. D. L., Saarela, M., and De Vos, W. M. (2001). Polymerase chain reaction and denaturing gradient gel electrophoresis monitoring of fecal bifidobacterium populations in a prebiotic and probiotic feeding trial. VTT Publ. 231, 85-89. doi: 10.1078/0723-2020-00035

Satpute, S. K., Banpurkar, A. G., Dhakephalkar, P. K., Banat, I. M., and Chopade, B. A. (2010). Methods for investigating biosurfactants and bioemulsifiers: a review. Crit. Rev. Biotechnol. 30, 127-144. doi: 10.3109/073885509034 27280

Satyanarayana, T., Prakash, A., and Johri, B. N. (2012). Microorganisms in Environmental Management: Microbes and Environment. Springer Netherlands.

Scow, K. M., and Hicks, K. A. (2005). Natural attenuation and enhanced bioremediation of organic contaminants in groundwater. Curr. Opin. Biotechnol. 16, 246-253. doi: 10.1016/j.copbio.2005.03.009

Sharma, A., and Rehman, M. B. (2009). Laboratory scale bioremediation of diesel hydrocarbon in soil by indigenous bacterial consortium. Indian J. Exp. Biol. 47, 766-769.
Shukla, N. (2017). Bioinformatics in environmental bioremediation - a review. Int J. Sci. Res. Sci. Eng. Technol. 3, 195-205.

Singh, O. V. (2006). Proteomics and metabolomics: the molecular makeup of toxic aromatic pollutant bioremediation. Proteomics 6, 5481-5492. doi: 10.1002/pmic.200600200

Singh, P., DeMarini, D. M., Dick, C. A. J., Tabor, D. G., Ryan, J. V., Linak, W. P., et al. (2004). Sample characterization of automobile and forklift diesel exhaust particles and comparative pulmonary toxicity in mice. Environ. Health Perspect. 112, 820-825. doi: 10.1289/ehp.6579

Smets, B. F., and Barkay, T. (2005). Horizontal gene transfer: perspectives at a crossroads of scientific disciplines. Nat. Rev. Microbiol. 3, 675-678. doi: $10.1038 /$ nrmicro 1253

Song, D. L., Conrad, M. E., Sorenson, K. S., and Alvarez-Cohen, L. (2002). Stable carbon isotope fractionation during enhanced in situ bioremediation of trichloroethene. Environ. Sci. Technol. 36, 2262-2268. doi: 10.1021/es011162d

Supaphol, S., Panichsakpatana, S., Trakulnaleamsai, S., Tungkananuruk, N., Roughjanajirapa, P., and O'Donnell, A. G. (2006). The selection of mixed microbial inocula in environmental biotechnology: example using petroleum contaminated tropical soils. J. Microbiol. Methods 65, 432441. doi: 10.1016/j.mimet.2005.09.001

Sutherland, W. J., Freckleton, R. P., Godfray, H. C. J., Beissinger, S. R., Benton, T., Cameron, D. D., et al. (2013). Identification of 100 fundamental ecological questions. J. Ecol. 101, 58-67. doi: 10.1111/1365-2745.12025

Tang, Y. J., Hwang, J. S., Wemmer, D. E., and Keasling, J. D. (2007). Shewanella oneidensis MR-1 fluxome under various oxygen conditions. Appl. Environ. Microbiol. 73, 718-729. doi: 10.1128/AEM.01532-06

Tang, Y. J., Martin, H. G., Dehal, P. S., Deutschbauer, A., Llora, X., Meadows, A., et al. (2009). Metabolic flux analysis of Shewanella spp. reveals evolutionary robustness in central carbon metabolism. Biotechnol. Bioeng. 102, 1161-1169. doi: 10.1002/bit.22129

Techtmann, S. M., and Hazen, T. C. (2016). Metagenomic applications in environmental monitoring and bioremediation. J. Ind. Microbiol. Biotechnol. 43, 1345-1354. doi: 10.1007/s10295-016-1809-8

Thijs, S., Van Hamme, J., Gkorezis, P., Rineau, F., Weyens, N., and Vangronsveld, J. (2014). Draft genome sequence of Raoultella ornithinolytica TNT, a trinitrotoluene-denitrating and plant growth-promoting strain isolated from explosive-contaminated soil. Genome Announc. 2:e00491-14. doi: 10.1128/genomeA.00491-14

Thomas, T., Gilbert, J., and Meyer, F. (2012). Metagenomics-a guide from sampling to data analysis. Microb. Inform. Exp. 2:3. doi: 10.1186/2042-5 783-2-3

Tripathi, M., Singh, D., Vikram, S., Singh, V., and Kumar, S. (2018). Metagenomic approach towards bioprospection of novel biomolecule(s) and environmental bioremediation. Annu. Res. Rev. Biol. 22, 1-12. doi: 10.9734/ARRB/2018/38385

Turnbaugh, P. J., Ley, R. E., Hamady, M., Fraser-Liggett, C. M., Knight, R., and Gordon, J. I. (2007). Feature the human microbiome project. Nature 449, 804-810. doi: 10.1038/nature06244

Tyson, G. W., Lo, I., Baker, B. J., Allen, E. E., Hugenholtz, P., and Banfield, J. F. (2005). Genome-directed isolation of the key nitrogen fixer Leptospirillum ferrodiazotrophum sp. nov. from an acidophilic microbial community. Appl. Environ. Microbiol. 71, 6319-6324. doi: 10.1128/AEM.71.10.6319-6324.2005

Ufarté, L., Laville, É., Duquesne, S., and Potocki-Veronese, G. (2015). Metagenomics for the discovery of pollutant degrading enzymes. Biotechnol. Adv. 33, 1845-1854. doi: 10.1016/j.biotechadv.2015.10.009

Utturkar, S. M., Bollmann, A., Brzoska, R. M., Klingeman, D. M., Epstein, S. E., and Palumbo, A., V (2013). Draft genome sequence for Ralstonia sp . strain OR214, a bacterium with potential for bioremediation. Genome Announc. 1:e00321-13. doi: 10.1128/genomeA.00321-13

Vácha, R., Skála, J., Cechmánková, J., Horváthová, V., and Hladík, J. (2015). Toxic elements and persistent organic pollutants derived from industrial emissions in agricultural soils of the Northern Czech Republic. J. Soils Sediments 15, 1813-1824. doi: 10.1007/s11368-015-1120-8

van der Meer, J. R., and Belkin, S. (2010). Where microbiology meets microengineering: design and applications of reporter bacteria. Nat. Rev. Microbiol. 8, 511-522. doi: 10.1038/nrmicro2392

van Dorst, J., Siciliano, S. D., Winsley, T., Snape, I., and Ferrari, B. C. (2014). Bacterial targets as potential indicators of diesel fuel toxicity in subantarctic soils. Appl. Environ. Microbiol. 80, 4021-4033. doi: 10.1128/AEM.03939-13 
Vartoukian, S. R., Palmer, R. M., and Wade, W. G. (2010). Strategies for culture of "unculturable"bacteria. FEMS Microbiol. Lett. 309, 1-7. doi: 10.1111/j.1574-6968.2010.02000.x

VerBerkmoes, N. C., Denef, V. J., Hettich, R. L., and Banfield, J. F. (2009a). Functional analysis of natural microbial consortia using community proteomics. Nat. Rev. Microbiol. 7, 196-205. doi: 10.1038/nrmicro2080

Verberkmoes, N. C., Russell, A. L., Shah, M., Godzik, A., Rosenquist, M., Halfvarson, J., et al. (2009b). Shotgun metaproteomics of the human distal gut microbiota. ISME J. 3, 179-189. doi: 10.1038/ismej. 2008.108

Vikram, S., Kumar, S., Vaidya, B., Pinnaka, A. K., and Raghava, G. P. S. (2013). Draft genome sequence of the 2-chloro-4-nitrophenol-degrading bacterium Arthrobacter sp. strain SJCon. Genome Announc. 1:e00058-13. doi: 10.1128/genomeA.00058-13

Villas-Bôas, S. G., and Bruheim, P. (2007). The potential of metabolomics tools in bioremediation studies. Omi. A J. Integr. Biol. 11, 305-313. doi: 10.1089/omi.2007.0005

Villas-Bôas, S. G., Koulman, A., and Lane, G. A. (2007). "Analytical methods from the perspective of method standardization," in Metabolomics, eds J. Nielsen and M. C. Jewett (Berlin; Heidelberg: Springer), 11-52.

Vorholt, J. A. (2012). Microbial life in the phyllosphere. Nat. Rev. Microbiol. 10, 828-840. doi: 10.1038/nrmicro2910

Wackett, L. P., and Hershberger, C. D. (2001). Biocatalysis and Biodegradation: Microbial Transformation of Organic Compounds. Washington, DC: ASM Press.

Weckwerth, W., and Fiehn, O. (2002). Can we discover novel pathways using metabolomic analysis? Curr. Opin. Biotechnol. 13, 156-160. doi: 10.1016/S0958-1669(02)00299-9

Werner, J. J., Ptak, A. C., Rahm, B. G., Zhang, S., and Richardson, R. E. (2009). Absolute quantification of Dehalococcoides proteins: enzyme bioindicators of chlorinated ethene dehalorespiration. Environ. Microbiol. 11, 2687-2697. doi: 10.1111/j.1462-2920.2009.01996.x

Wharfe, E. S., Jarvis, R. M., Winder, C. L., Whiteley, A. S., and Goodacre, R. (2010). Fourier transform infrared spectroscopy as a metabolite fingerprinting tool for monitoring the phenotypic changes in complex bacterial communities capable of degrading phenol. Environ. Microbiol. 12, 3253-3263. doi: 10.1111/j.1462-2920.2010.02300.x

Wicker, J., Lorsbach, T., Gütlein, M., Schmid, E., Latino, D., Kramer, S., et al. (2016). enviPath-The environmental contaminant biotransformation pathway resource. Nucleic Acids Res. 44, D502-D508. doi: 10.1093/nar/gkv1229

Wiechert, W., Schweissgut, O., Takanaga, H., and Frommer, W. B. (2007). Fluxomics: mass spectrometry versus quantitative imaging. Curr. Opin. Plant Biol. 10, 323-330. doi: 10.1016/j.pbi.2007.04.015
Wilmes, P., and Bond, P. L. (2004). The application of two-dimensional polyacrylamide gel electrophoresis and downstream analyses to a mixed community of prokaryotic microorganisms. Environ. Microbiol. 6, 911-920. doi: 10.1111/j.1462-2920.2004.00687.x

Winderl, C., Schaefer, S., and Lueders, T. (2007). Detection of anaerobic toluene and hydrocarbon degraders in contaminated aquifers using benzylsuccinate synthase (bssA) genes as a functional marker. Environ. Microbiol. 9, 1035-1046. doi: 10.1111/j.1462-2920.2006.01230.x

Yang, Y., Yu, X., and Zhang, R. (2013). Draft genome sequence of Ochrobactrum pseudogrignonense strain CDB2, a highly efficient arsenate-resistant soil bacterium from arsenic-contaminated cattle dip sites. Genome Announc. 1:e00173-13. doi: 10.1128/genomeA.00173-13

Yang, Y., and Zhang, R. (2017). Draft genome sequence of bacillus sp. strain $\mathrm{CDB} 3$, an arsenic-resistant soil bacterium isolated from cattle dip sites. Genome Announc. 5:e00429-17. doi: 10.1128/genomeA.00429-17

Yooseph, S., Sutton, G., Rusch, D. B., Halpern, A. L., Williamson, S. J., Remington, K., et al. (2007). The sorcerer II global ocean sampling expedition: expanding the universe of protein families. PLoS Biol. 5:e16. doi: 10.1371/journal.pbio.0050016

Zhao, B., Yeo, C. C., and Poh, C. L. (2005). Proteome investigation of the global regulatory role of $\sigma 54$ in response to gentisate induction in Pseudomonas alcaligenes NCIMB 9867. Proteomics 5, 1868-1876. doi: 10.1002/pmic.200401081

Zhou, J., He, Q., Hemme, C. L., Mukhopadhyay, A., Hillesland, K., Zhou, A., et al. (2011). How sulphate-reducing microorganisms cope with stress: lessons from systems biology. Nat. Rev. Microbiol. 9, 452-466. doi: 10.1038/nrmicro2575

Ziganshina, E. E., Mohammed, W. S., Doijad, S. P., Shagimardanova, E. I., Gogoleva, N. E., and Ziganshin, A. M. (2018). Draft genome sequence of Brevibacterium epidermidis EZ-K02 isolated from nitrocellulose-contaminated wastewater environments. Data Br. 17, 119-123. doi: 10.1016/j.dib.2017. 12.053

Conflict of Interest Statement: The authors declare that the research was conducted in the absence of any commercial or financial relationships that could be construed as a potential conflict of interest.

Copyright (C) 2018 Malla, Dubey, Yadav, Kumar, Hashem and Abd_Allah. This is an open-access article distributed under the terms of the Creative Commons Attribution License (CC BY). The use, distribution or reproduction in other forums is permitted, provided the original author(s) and the copyright owner are credited and that the original publication in this journal is cited, in accordance with accepted academic practice. No use, distribution or reproduction is permitted which does not comply with these terms. 